\title{
Lemon Juice Assisted Green Synthesis of Reduced Graphene Oxide and Its Application for Adsorption of Methylene Blue
}

\author{
Md. Mahiuddin (D) and Bungo Ochiai *(D) \\ Department of Chemistry and Chemical Engineering, Graduate School of Science and Engineering, \\ Yamagata University, Jonan 4-3-16, Yonezawa, Yamagata 992-8510, Japan; mahiuddinmithun@yahoo.com \\ * Correspondence: ochiai@yz.yamagata-u.ac.jp; Tel.: +81-0238-26-3092
}

check for updates

Citation: Mahiuddin, M.; Ochiai, B.

Lemon Juice Assisted Green

Synthesis of Reduced Graphene

Oxide and Its Application for

Adsorption of Methylene Blue.

Technologies 2021, 9, 96. https://

doi.org/10.3390/technologies9040096

Academic Editor: Shin-ichi Yusa

Received: 12 October 2021

Accepted: 29 November 2021

Published: 2 December 2021

Publisher's Note: MDPI stays neutral with regard to jurisdictional claims in published maps and institutional affiliations.

Copyright: (c) 2021 by the authors. Licensee MDPI, Basel, Switzerland. This article is an open access article distributed under the terms and conditions of the Creative Commons Attribution (CC BY) license (https:/ / creativecommons.org/licenses/by/ $4.0 /)$.

\begin{abstract}
Sustainable synthesis of reduced graphene oxide (rGO) is of crucial significance within the development of carbon nanomaterials. In this study, a green and eco-friendly strategy for the synthesis of rGO using lemon juice as the reducing agent for graphene oxide (GO) without using toxic and harmful chemicals was demonstrated. The reduction with lemon juice effectively eliminated the oxygen-containing functionalities of GO and regenerated the conjugated systems as confirmed by the UV-vis and FTIR spectroscopic and X-ray diffraction analyses. Microscopic evaluation showed the successful manufacturing of exfoliated and separated few layers of nano-sheets of rGO. The application of the resultant rGO as an adsorbent for organic pollutants was investigated using methylene blue (MB) as a model. The adsorption kinetics of MB on rGO is best matched with the pseudo-second-ordered kinetic model and the Langmuir model with a high adsorption capacity of $132.2 \mathrm{mg} / \mathrm{g}$. The rGO exhibited good reusability with a removal efficiency of $80.4 \%$ in the fourth cycle. This green method provides a new prospect for the large-scale production of rGO in a cost-effective and safe manner.
\end{abstract}

Keywords: lemon juice; green synthesis; reduced graphene oxide; pollutants; adsorption

\section{Introduction}

The discovery of graphene [1] changed the scenario of the research world of nanomaterials. Graphene and its derivatives have become one of the most fascinating and hottest research topics in the empire of carbon nanomaterials [1-9], because of their versatile properties like high surface area, high mechanical strength, and excellent electrical and thermal conductivities, and promising applications in the field of material science and engineering, including energy storage, catalysis, drug delivery, sensing and biosensing, and water treatment [10-18] Various methods have been employed to produce graphene and its analogue, reduced graphene oxide (rGO). In particular, chemical reduction of exfoliated graphene oxide (GO) is efficient and advantageous in the large-scale production of rGO, because high-quality rGO with a relatively lower oxygen content can be obtained at a low cost in a short time $[19,20]$. Despite the significant advantages of this method, uses of toxic and dangerously unstable reducing agents including sodium borohydride [21], hydrazine and its derivatives [22,23], hydroquinone [24], and hydrogen sulfide [25] are a major limitation due to the requirements of exceptional care for handling and environmental hazard. Therefore, environmentally friendly and facile alternative methods are highly demanded to resolve the above-mentioned limitations. Aqueous-phase reduction of GO, utilizing safe and abundant natural sources as reducing agents, is a pioneering approach for efficient green and facile methods [2,3,26,27]. Among the various natural sources, plants allow scalable, safe, and cost-effective processes. Reported plant sources as reducing agents for the reduction of GO to rGO include green tea [6], mango leaves and potato [28], Aloe vera [29], eucalyptus bark [30], sugarcane bagasse [31], kaffir lime peel [32], Terminalia chebula seed [33], and rose water [34]. These green-synthesized rGOs were investigated for applications in sensing, photocatalysis, electrochemical charge storage, etc. Furthermore, 
some of these green synthesized rGOs have the tremendous ability to adsorb organic dyes $[29,31,32,35]$. Although a lot of plants have been investigated, plant sources accessible regardless of the region are still attractive for practical uses.

Lemons have a special taste and aroma and are extensively fed on globally. Lemon [Citrus limon (L.) Burm] is the second maximum planted citrus fruit [36]. As of 2016, India has been the world's main lemon producer with 2.98 million tons of yearly manufacturing, while Mexico secured the second position with 2.43 million tons, and China become third with 2.33 million tons (www.atlasbig.com) (accessed on 8 October 2021) [37]. The huge production of lemons represents its high commercial value and consumption flow. Lemons are rich in phytochemicals including ascorbic acid, citric acid, sugars, and polyphenols [38-41] that can serve as reducing agents for the synthesis of various metal nanoparticles from their corresponding metal ions [42-44]. Specifically, the high contents of ascorbic and citric acids in lemons are well known, and the detail of the typical composition of lemon juice is summarized in a review by Szopa et al. [45]. Gurbani et al. employed a biogenic strategy for the fabrication of rGO using lemon juice [46]. The rGO based on lemon juice hybridized with Pt exhibits a higher catalytic ability in hydrogen production by water splitting than rGO prepared by reduction with ascorbic acid, while the optimization of synthetic conditions has not been addressed.

Therefore, in this paper, we demonstrate the preparation of rGO using lemon juice as an abundant, efficient, and economical reducing agent through a simple, ecofriendly, and cost-effective approach by optimizing the synthetic conditions and application of the obtained rGO as a potential adsorbent for the removal of dyes using methylene blue (MB) as a model compound.

\section{Materials and Methods}

\subsection{Collection of Lemon Juice}

Yellow lemon was purchased from a supermarket in Yonezawa city of Yamagata prefecture, Japan, and thoroughly washed with deionized distilled water. The juice was collected by squeezing the lemon followed by centrifugation (13,000 rpm, $10 \mathrm{~min})$ and filtration, and finally stored at $4{ }^{\circ} \mathrm{C}$ for further use.

\subsection{Materials}

Graphite powder purchased from Sigma-Aldrich (St. Louis, MO, USA). Sodium borohydride $\left(\mathrm{NaBH}_{4}\right)$, sodium nitrate $\left(\mathrm{NaNO}_{3}\right)$, hydrogen peroxide $\left(\mathrm{H}_{2} \mathrm{O}_{2}\right)$, sulfuric acid $\left(\mathrm{H}_{2} \mathrm{SO}_{4}\right), \mathrm{MB}$, and sodium hydroxide $(\mathrm{NaOH})$ were purchased from Kanto Chemical Co. Inc. (Tokyo, Japan). Potassium permanganate $\left(\mathrm{KMnO}_{4}\right)$ was obtained from Tokyo Chemical Industry Co. Ltd. (Tokyo, Japan). All of the reagents were of analytical grade and were used directly without further purification. Deionized (DI) water was used throughout the study.

\subsection{Measurements}

UV-vis spectroscopic analysis was carried out on a HACH (Loveland, CO, USA) DR 5000 spectrometer. Absorption spectra were recorded at a resolution of $1 \mathrm{~nm}$ within 200-800 nm. Fourier-transform infrared (FTIR) spectra were recorded on a Shimadzu (Tokyo, Japan) IRSprit spectrometer equipped with a Shimadzu QATR-S single-reflection ATR accessory and a diamond prism with 32 scans (both for sample and air background) and a scan rate of $4 \mathrm{~cm}^{-1} \mathrm{~s}^{-1}$ approximately at $25{ }^{\circ} \mathrm{C}$ in the range of 400 to $4000 \mathrm{~cm}^{-1}$. Approximately $0.5 \mathrm{mg}$ of samples were used for the measurements. Scanning electron microscopy (SEM) measurement was conducted on a Hitachi (Tokyo, Japan) SU-8000 microscope at accelerating voltages of 10 and $15 \mathrm{kV}$. Energy-dispersive X-ray spectroscopy (EDX) analysis was conducted on a JEOL (Tokyo, Japan) JSM-6510A analytical scanning electron microscope equipped with a JEOL JED2300 EDX spectrometer operated at an acceleration voltage of $10 \mathrm{kV}$ using sample as a compressed disk placed on an SEM pin with the help of double-sided carbon tape. Transmission electron microscopy (TEM) 
measurement was conducted on a JEOL TEM-2100F field emission electron microscope. X-ray diffraction (XRD) analysis was conducted on a Rigaku (Tokyo, Japan) MiniFlex 600 diffractometer with $\mathrm{Cu}-\mathrm{K} \alpha$ radiation. Raman spectra were recorded on a JASCO (Tokyo, Japan) RPM-320 spectrometer with a laser of $532 \mathrm{~nm}$ using powder samples. Thermogravimetric analysis (TGA) was carried out on a Seiko Instruments (Tokyo, Japan) TG/DTA 6200 (EXSTER6000) at a heating rate of $10^{\circ} \mathrm{C} \min ^{-1}$ under $\mathrm{N}_{2}$.

\subsection{Synthesis of Graphene Oxide (GO)}

GO was prepared by a modified Hummer's method based on previous reports [28,47]. Briefly, $2 \mathrm{gm}$ of graphite powder was mixed with $80 \mathrm{~mL}$ of concentrated sulfuric acid under ice bath conditions by maintaining the temperature below $0-5{ }^{\circ} \mathrm{C}$. After $30 \mathrm{~min}, 2 \mathrm{gm}$ of sodium nitrate was added, and the mixture was stirred for $1 \mathrm{~h}$. Then, $12 \mathrm{gm}$ of $\mathrm{KMnO}_{4}$ was added slowly to the mixture, and the temperature was controlled below $10{ }^{\circ} \mathrm{C}$ with stirring for $1 \mathrm{~h}$. Subsequently, the flask was transferred to an oil bath, maintained at $40{ }^{\circ} \mathrm{C}$, and the mixture was constantly stirred for $2 \mathrm{~h}$. After the addition of $80 \mathrm{~mL}$ of water, the mixture was stirred for another $1 \mathrm{~h}$ at $90^{\circ} \mathrm{C}$, and then, at room temperature overnight. To control the $\mathrm{pH}$ of the reaction medium and to terminate the reaction, $180 \mathrm{~mL}$ of water and $20 \mathrm{~mL}$ of $\mathrm{H}_{2} \mathrm{O}_{2}$ were sequentially added to the reaction mixture. The color of the suspension changed from brown to light yellow indicating oxidation of graphite to GO. After centrifugation of the solution at 10,000 rpm for $10 \mathrm{~min}$, GO was washed with $2 \mathrm{M}$ $\mathrm{HCl}$ to remove metal ions and with distilled water several times. The resulting GO was vacuum-dried at $50^{\circ} \mathrm{C}$ for $24 \mathrm{~h}$ and stored for further use for the preparation of rGO.

\subsection{Green Synthesis of rGO Using Lemon Juice (Typical Procedure)}

GO (50 mg) was mixed with $20 \mathrm{~mL}$ of lemon juice by sonication, and the $\mathrm{pH}$ of the mixture was adjusted to 12.3 using $4 \mathrm{M}$ aqueous $\mathrm{NaOH}$. Then, the mixture was stirred in an oil bath at $80^{\circ} \mathrm{C}$ for $2 \mathrm{~h}$. After that, the resultant black product was collected by centrifugation and washed with water four times. Then, the product was vacuum-dried for $24 \mathrm{~h}$ at $50{ }^{\circ} \mathrm{C}$ and stored at $25^{\circ} \mathrm{C}$ for further use.

\subsection{Preparation of Methylene Blue (MB) Solutions}

A stock solution of $1000 \mathrm{mg} / \mathrm{L} \mathrm{MB}$ was made by dissolving MB powder in water. The solution used in the experiments was prepared by diluting the stock solution.

\subsection{The Adsorption of $M B$ on $r G O$}

To evaluate the adsorption kinetics and the effect of contact time (batch tests), adsorption of MB was carried out by adding $15 \mathrm{mg}$ of rGO into $100 \mathrm{~mL}$ of $20 \mathrm{mg} / \mathrm{L} \mathrm{MB}$ solution in a $200 \mathrm{~mL}$ round bottom flask. The resulting mixture was stirred at $150 \mathrm{rpm}$ using a magnetic stirrer up to $2.5 \mathrm{~h}$ at three different temperatures $\left(25,40\right.$, and $\left.60{ }^{\circ} \mathrm{C}\right)$. At the specified time, rGO was precipitated by centrifugation at $10,000 \mathrm{rpm}$ for $5 \mathrm{~min}$, and the final concentration of $\mathrm{MB}$ in the supernatant was determined from optical absorption at $665 \mathrm{~nm}$. Similarly, adsorption isotherm was obtained by batch experiments adding $10 \mathrm{mg}$ of rGO in $100 \mathrm{~mL}$ of MB solutions with different concentrations in the range of 8-20 mg/L with the step of $2 \mathrm{mg} / \mathrm{L}$ at $25^{\circ} \mathrm{C}$. Dependence of removal of $\mathrm{MB}$ on the mass of $\mathrm{rGO}$ was determined by using different addition masses of $\mathrm{rGO}$ (4-9 $\mathrm{mg}$ with the step of $1 \mathrm{mg}$ ) into a series of Erlenmeyer flasks, which contain $50 \mathrm{~mL}$ of $20 \mathrm{mg} / \mathrm{L} \mathrm{MB}$ solution. The effect of $\mathrm{pH}$ in the range of 2-9 (step size: 1 ) was studied by adding $8 \mathrm{mg}$ of rGO in $100 \mathrm{~mL}$ of $16 \mathrm{mg} / \mathrm{L} \mathrm{MB}$ solution at $25^{\circ} \mathrm{C}$. The initial $\mathrm{pH}$ of the $\mathrm{MB}$ solution was adjusted by $\mathrm{HCl}$ $(0.1 \mathrm{M})$ and $\mathrm{NaOH}(0.1 \mathrm{M})$.

The adsorption capacity ( $q_{t}$, the amount of adsorbed MB per unit mass of adsorbent) of rGO was calculated by the following equation [35]:

$$
q_{t}=\frac{\left(C_{0}-C_{t}\right) V}{W}
$$


where $C_{0}$ and $C_{t}$ are the concentrations $(\mathrm{mg} / \mathrm{L}) \mathrm{MB}$ at initial and at time $t$, respectively; $V$ represents the volume of the solution $(\mathrm{L}) ;$ and $W$ is the adsorbent mass $(\mathrm{g}) . C_{e}(\mathrm{mg} / \mathrm{L})$ and $q_{e}$ denotes the equilibrium concentration and the equilibrium adsorption capacity, respectively. The removal efficiency $(R E \%)$ was calculated by the following equation [35,48]:

$$
R E \%=\frac{\left(C_{0}-C_{e}\right)}{C_{0}} \times 100
$$

\section{Results and Discussion}

\subsection{Characterization}

The reduction of GO to rGO was carried out using lemon juice as an efficient and economical green reducing agent. The change of the color of the reaction mixture from brownish to deep black indicates the reduction of GO. The reduction of GO to produce rGO was first confirmed by UV-vis spectroscopy with the characteristic absorption peaks of GO and rGO (Figure 1). We employed rGO prepared by the reduction of GO with lemon juice at $80^{\circ} \mathrm{C}$ for $2 \mathrm{~h}$. The absorption spectrum of GO exhibits a peak at $231 \mathrm{~nm}$ corresponding to the $\pi-\pi^{*}$ transitions, whereas the spectrum of rGO shows a broad absorption peak around $272 \mathrm{~nm}$ due to the $\pi-\pi *$ transitions of more conjugated double bonds [30]. In addition, the cut-off wavelength significantly shifted to the infrared region. This change indicates that the conjugated structures were regenerated by the reductive removal of oxygen functionalities in GO cleaving the conjugated system.
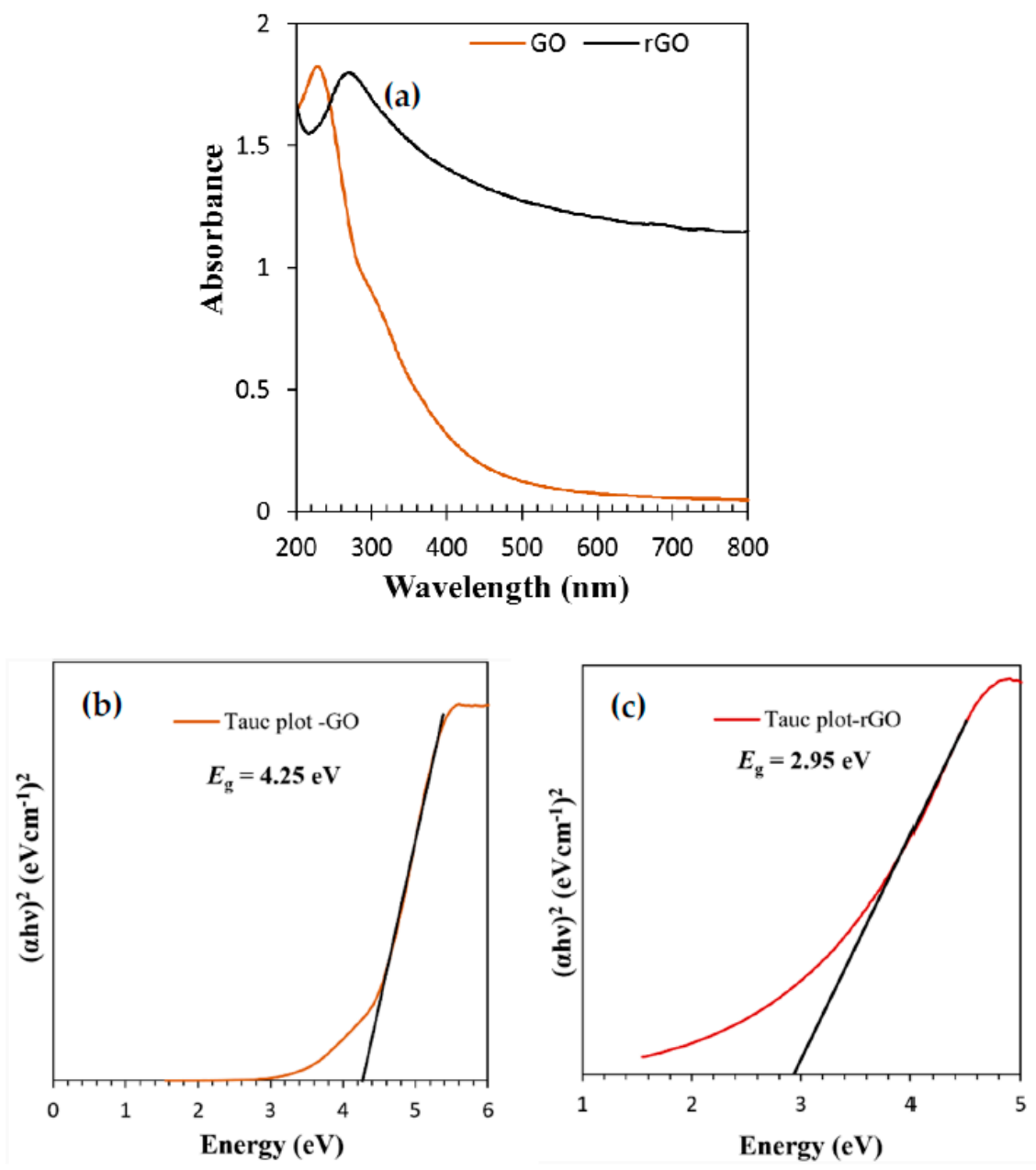

Figure 1. (a) UV-vis spectra of GO and rGO synthesized using lemon juice (conditions: $\mathrm{pH}=12.3$, $80{ }^{\circ} \mathrm{C}$, and $2 \mathrm{~h}$; dispersed in water) and Tauc plots of (b) GO and (c) rGO for the optical band gap determination. 
The optical band gap energy was estimated from UV-vis results using the following Tauc's expression [49]:

$$
\alpha h v=B\left(h v-E_{g}\right)^{m}
$$

where $\alpha$ is the absorption coefficient, $B$ is a constant, $h v$ is the photon energy, $E_{\mathrm{g}}$ is the optical band gap and $m=\frac{1}{2}$ for direct allowed transitions. The optical band gap was obtained from the extrapolation of the linear region to the x-axis of the $(\alpha h v)^{2}$ vs. $h v$ plot (Figure 1b,c). The optical band gap of GO decreases from $4.25 \mathrm{eV}$ to $2.95 \mathrm{eV}$ upon the reduction by lemon juice, supporting the formation of rGO. A similar trend was reported for the reduction of GO using the gas-based hydrazine method by Mathkar et al. [50] and for the reduction of GO using mild reagents (glucose, fructose, and ascorbic acid) by Velasco-Soto et al. [51].

The time-dependent progress of the reaction was monitored by UV-vis spectroscopy (Figure 2). The absorption maxima red-shifted as time with the increasing of the absorption intensity. The spectra show that the red shift reaches the characteristic peak of rGO at $272 \mathrm{~nm}$ at $30 \mathrm{~min}$ and that the intensity becomes identical, suggesting the completion of the reduction. The slight difference in the peak intensity probably originates from the sedimentation of rGO during the reaction and measurement due to the low dispersibility as the loss of the functional groups by the reduction.

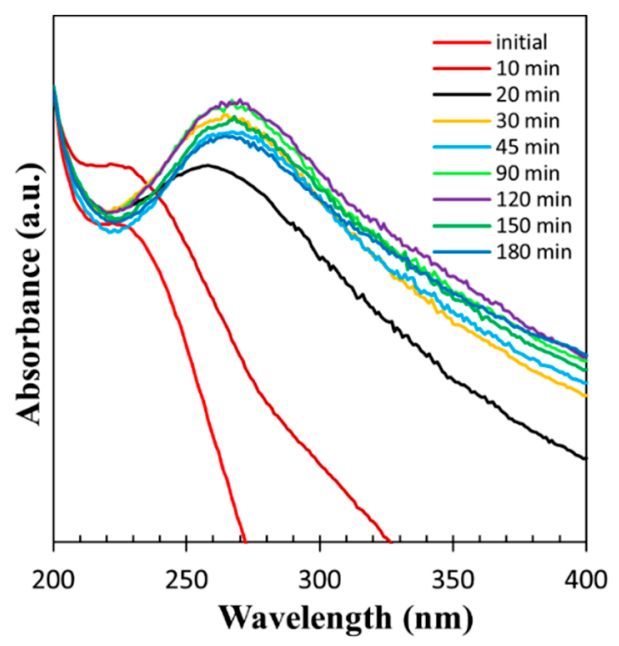

Figure 2. Time-dependent UV-vis spectra of the reaction mixture of the reduction of GO to rGO using lemon juice (conditions: $\mathrm{pH}=12.3$ and $80^{\circ} \mathrm{C}$ ).

To understand the role of temperature on the reduction of GO by lemon juice, the reaction was conducted at different temperatures and the obtained rGO was characterized by UV-vis and FTIR spectroscopy and XRD analysis (discussed later). UV-vis absorption spectra of reaction mixtures (Figure 3) show that the intensity of absorption maxima increased as the temperature increased, indicating speeding up of the reduction.

The surface functionality of GO and rGO was evaluated by FTIR analysis. Figure 4 shows the FTIR spectra of GO and rGO synthesized using lemon juice at different temperatures, clearly reflecting the removal of the oxygen functionalities in GO. 


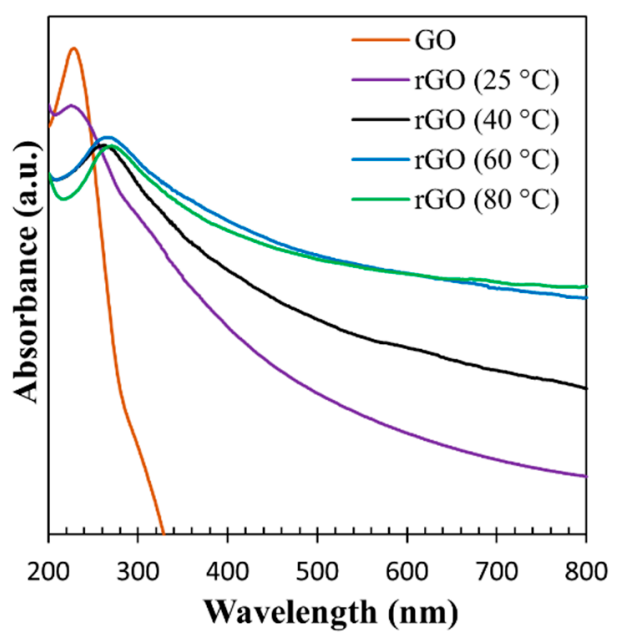

Figure 3. UV-vis spectra of the reaction mixture of the reduction of GO to rGO using lemon juice at different temperatures (conditions: $\mathrm{pH}=12.3$ and $2 \mathrm{~h}$ ).

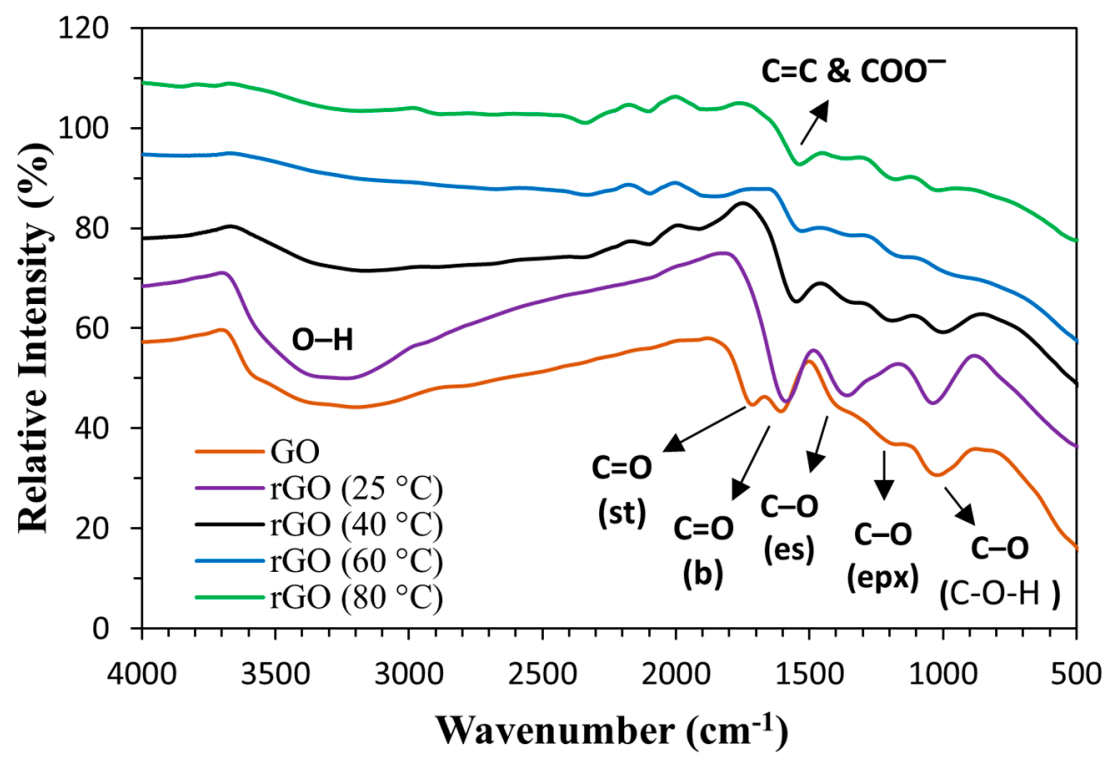

Figure 4. FTIR spectra of GO and rGO synthesized using lemon juice at different temperatures (conditions: $\mathrm{pH}=12.3$ and $2 \mathrm{~h}$ ).

The spectrum of GO exhibits a broad band at $3447 \mathrm{~cm}^{-1}$ of the $\mathrm{O}-\mathrm{H}$ stretching of the hydroxyl group $[17,28,52]$; sharp peaks of the $\mathrm{C}=\mathrm{O}$ stretching at $1705 \mathrm{~cm}^{-1}[15,28]$ and $\mathrm{C}=\mathrm{O}$ bending at $1610 \mathrm{~cm}^{-1}$ [28]; and $\mathrm{C}-\mathrm{O}$ stretching of $\mathrm{C}-\mathrm{O}-\mathrm{H}$ stretching at $1056 \mathrm{~cm}^{-1}$, ester group (C-O) at $1398 \mathrm{~cm}^{-1}$, and epoxy groups at $1215 \mathrm{~cm}^{-1}[3,6,52,53]$. In the spectra of rGO, the peaks at $1705 \mathrm{~cm}^{-1}$ are completely unobservable, while the intensities of the peaks at $1056 \mathrm{~cm}^{-1}$ and $3447 \mathrm{~cm}^{-1}$ gradually decreased due to the accelerated reduction of $\mathrm{GO}$ as the temperature increased. The signals finally became almost unobservable as can be confirmed by the low signal to noise ratios, indicating that the oxygen functionalities are adequately removed in comparison to the previously reported rGO based on lemon juice [46]. The intensity of detectable peaks that appeared in the range of $1000-1400 \mathrm{~cm}^{-1}$ was considerably weaker. By contrast, the peak at $1570 \mathrm{~cm}^{-1}$ unobservable for GO is assignable to the in-plane vibration of the $\mathrm{C}=\mathrm{C}$ skeleton and adsorbed phytochemicals, mainly carboxylate moieties of lemon juice [44]. These changes in FTIR spectra clearly indicate that GO was successfully reduced to $\mathrm{rGO}$ and higher temperatures make GO reduction more convenient. 
To characterize the interlayer spacing and crystal structure, powder XRD analysis was carried out. Figure 5 shows the XRD patterns of graphite powder, GO, and rGO synthesized using lemon juice at different temperatures.

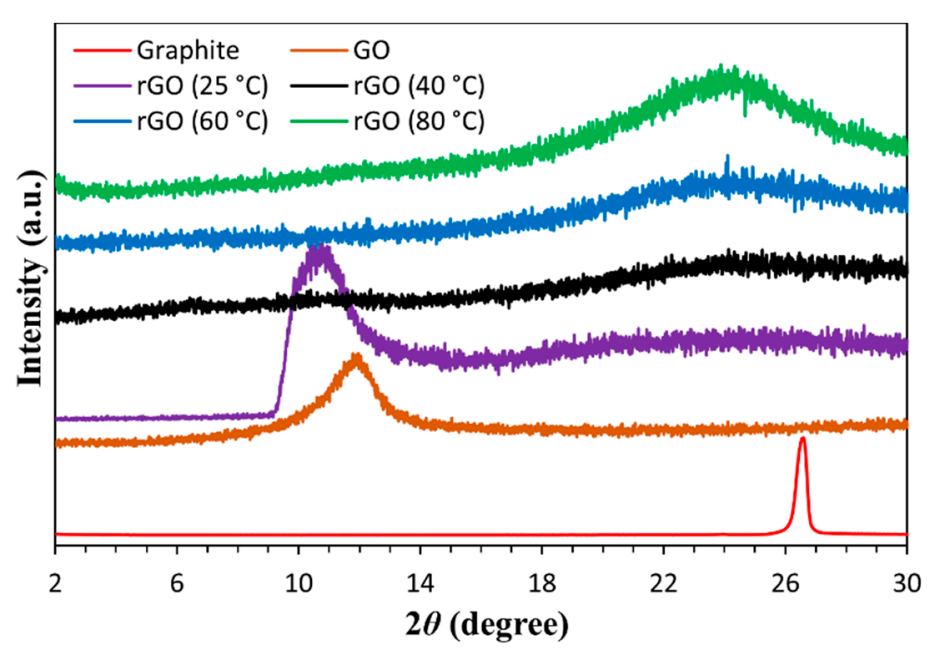

Figure 5. XRD patterns of graphite powder, GO and rGO synthesized using lemon juice at different temperatures (conditions: $\mathrm{pH}=12.3$ and $2 \mathrm{~h}$ ).

The XRD pattern of graphite powder exhibits a characteristic diffraction peak at $26.6^{\circ}$ corresponding to the basal reflection (002) with an interlayer d-spacing of $0.335 \mathrm{~nm}$ [30]. On the other hand, the diffraction peak of GO appeared at a lower diffraction angle of $12.04^{\circ}$ with interlayer $\mathrm{d}$-spacing of $0.734 \mathrm{~nm}$ widened the presence of functional groups and the intercalation of water molecules. The XRD patterns of rGO prepared by the reduction of $\mathrm{GO}$ with lemon juice at different temperatures shows a broad peak approximately at $24^{\circ}$. At lower temperatures, the GO peak is still observed with a broad shoulder of the characteristic peak of $\mathrm{rGO}$, indicating the incomplete reduction of GO. As the temperature increased the sharpness and intensity of the peak improved. At $80^{\circ} \mathrm{C}$, the peak was observed at $24.26^{\circ}$ with interlayer d-spacing of $0.367 \mathrm{~nm}$, while the diffraction peak at $12.04^{\circ}$ [30] was unobservable, indicating the completion of GO reduction. This interlayer spacing of rGO, identical to those of previously reported $\mathrm{rGO}$ and close to that of graphite, indicates the efficient removal of oxygen functionalities of $\mathrm{GO}$ by reduction $[6,30,54]$. However, the shape of the characteristic diffraction of rGO produced in this work is broader than the previously reported lemon-juice-based rGO, showing both shape and broad peaks [46]. The sharp peak is assignable to the graphitic structure that remained unreacted in the GO precursor, and the sufficient oxidation to GO probably resulted in the formation of wellexfoliated rGO in this work. The broad and weak (002) reflection of rGO is also attributed to a small size $(<1 \mu \mathrm{m})$ and disordered stacking of rGO sheets, as similarly reported by Penki et al. [55].

Overall, at $25^{\circ} \mathrm{C}$, all the analytical data indicate that the reaction does not proceeds insufficiently and that the product partially contains the GO structure. At $40{ }^{\circ} \mathrm{C}$, the UVvis and IR spectra show that the reaction proceed more than $25^{\circ} \mathrm{C}$ but less than $60{ }^{\circ} \mathrm{C}$, and the XRD profile shows the absence of the diffraction originating from layers of GO. The identical UV-vis spectra of the products obtained at 60 and $80{ }^{\circ} \mathrm{C}$ indicate that the conjugation length of $\mathrm{rGO}$ reached effective conjugation length of UV-vis spectroscopy. The XRD profiles indicate that the diffraction of $\mathrm{rGO}$ obtained at $80{ }^{\circ} \mathrm{C}$ is clearer than that obtained at $60{ }^{\circ} \mathrm{C}$ containing a trace amount of functional groups as confirmed by the IR spectra. Therefore, the rGO synthesized at $80{ }^{\circ} \mathrm{C}$ for $2 \mathrm{~h}$ was used for further characterizations and adsorption study.

Electron microscopy analysis was employed for morphological studies of the obtained rGO. Figure 6 shows the SEM images GO and rGO. The SEM image of GO shows 
the 3D-stacked layers of GO sheets. By contrast, the SEM image of rGO shows exfoliated and separated few layers of sheets in a similar manner with previously reported rGO $[31,35,52,56]$.
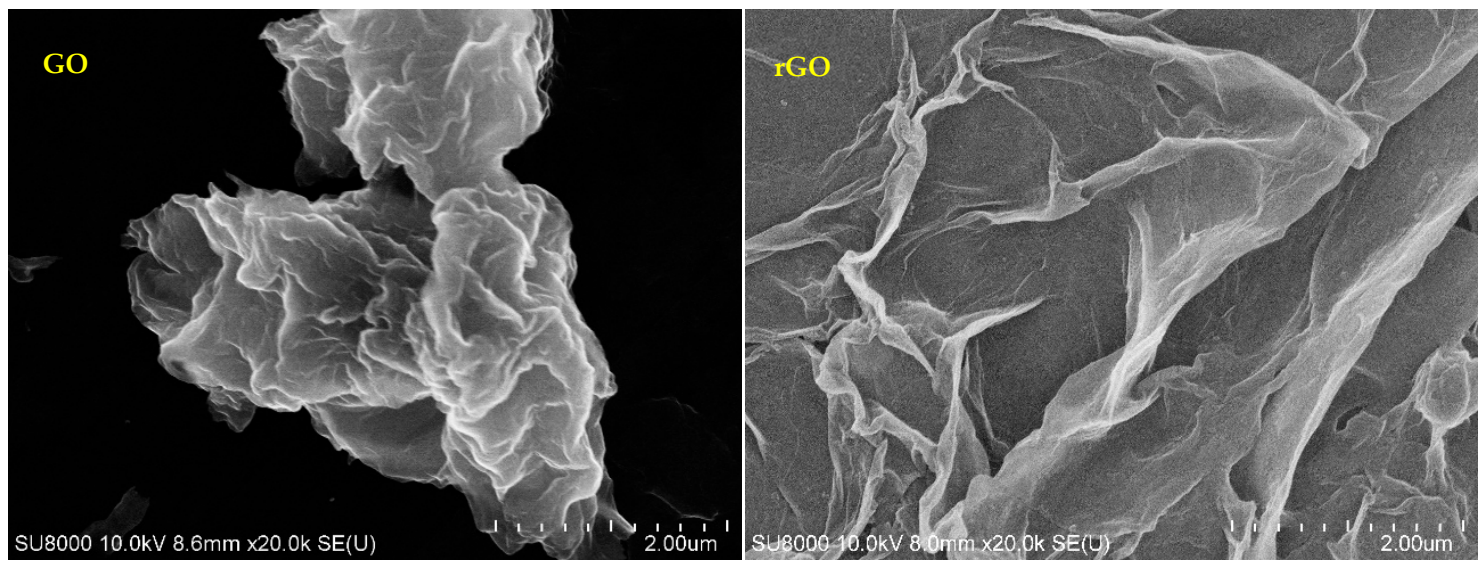

Figure 6. SEM images of GO and rGO synthesized using lemon juice.

The TEM image (Figure 7) also proved that the lemon juice-based synthetic process successfully produced exfoliated nano-sheets of rGO. The number of layers of 2D nanosheets of rGO cannot be determined exactly, but the absence of graphitic aggregates indicates the efficient formation of exfoliated rGO sheets.
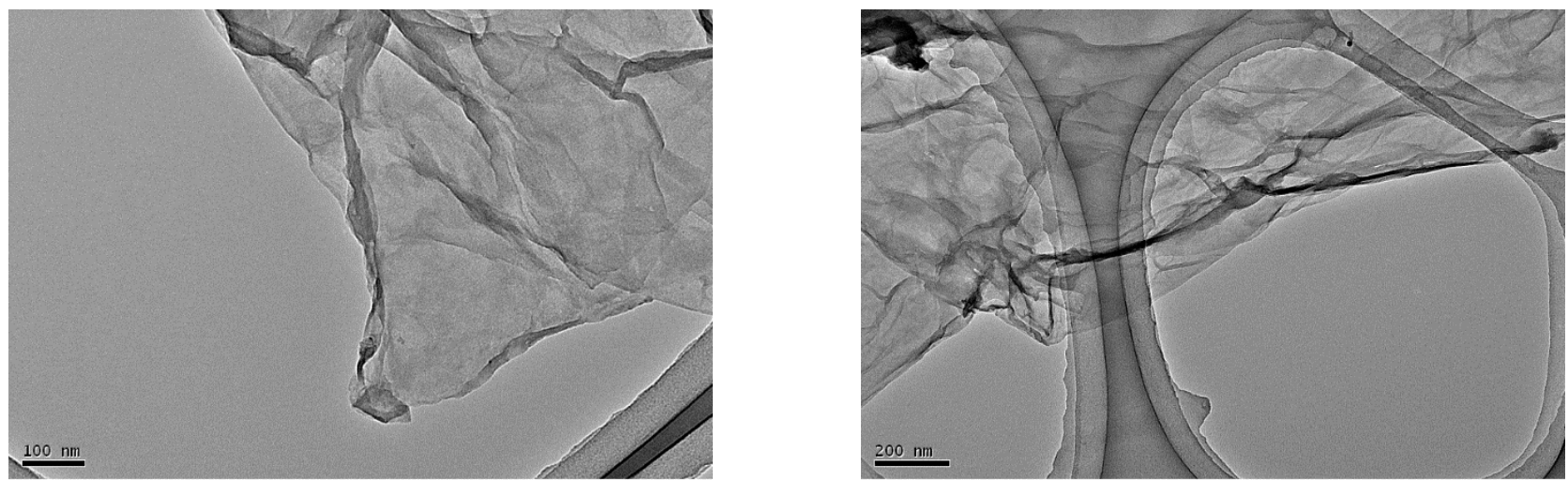

Figure 7. TEM images of rGO synthesized using lemon juice.

A qualitative analysis of the graphene structures in GO and rGO synthesized using lemon juice was carried out by Raman spectroscopy (Figure 8). The Raman spectra of GO exhibited the $D$ and $G$ bands as the major characteristic bands at $1348 \mathrm{~cm}^{-1}$ and $1589 \mathrm{~cm}^{-1}$, respectively, which are shifted to $1344 \mathrm{~cm}^{-1}$ (D band) and $1574 \mathrm{~cm}^{-1}$ (G band) after reduction. This behavior complies with the previously reported works $[52,53,57,58]$. The $\mathrm{D}$ band corresponding to $\mathrm{sp}^{3}$ carbon atoms results from the formation of structural defects, whereas the $\mathrm{G}$ band referred to the vibration of $\mathrm{sp}^{2}$ carbon atoms. The intensity ratio of the $\mathrm{D}$ band and $\mathrm{G}$ band $\left(I_{\mathrm{D}} / I_{\mathrm{G}}\right)$ can be used to estimate the degree of disorder in the graphitic structure $[3,58]$, where the higher $I_{\mathrm{D}} / I_{\mathrm{G}}$ values of $\mathrm{rGO}$ than their counterparts suggest a high degree of disorder, in contrast, the lower values indicate fewer defects [56,59-61]. As shown in Figure 8 , the $I_{\mathrm{D}} / I_{\mathrm{G}}$ value of rGO is calculated to be 1.05 , which is closely resembles the value of GO (1.04), indicating that the obtained rGO contains a structural disorder almost identical to GO. Whereas previously reported lemon juice-based rGO (0.99) exhibited fewer structural defects than GO (0.83) [46], it is unable to compare the difference with this work due to the presence of the graphitic domain in GO in the previous work. 


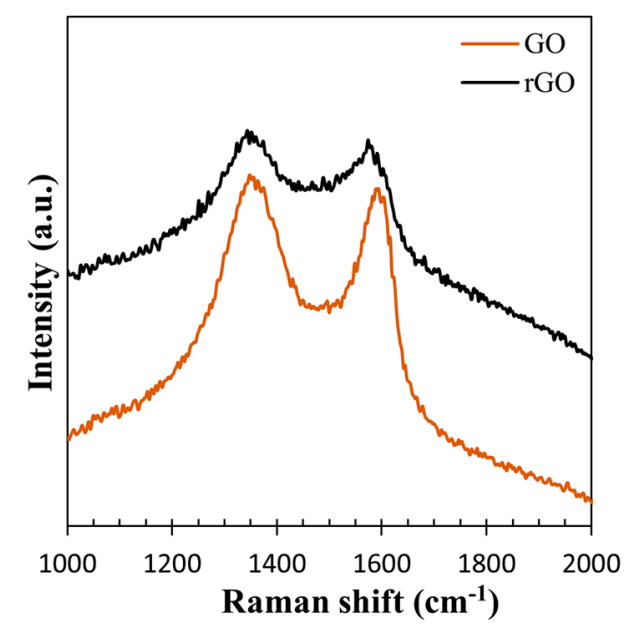

Figure 8. Raman spectra of GO and rGO synthesized using lemon juice.

Figure 9 illustrates the EDX spectra of rGO synthesized using lemon juice and GO. The spectrum of $\mathrm{rGO}(\mathrm{C}=81 \%, \mathrm{O}=16 \%$, and $\mathrm{Na}=3 \%)$ exhibits a higher intensity ratio of carbon to oxygen than that of $\mathrm{GO}(\mathrm{C}=61 \%$ and $\mathrm{O}=39 \%)$. The higher intensity ratio of carbon to oxygen originated from the elimination of the oxygen functionalities in GO during the reduction process, confirming the formation of rGO using lemon juice. In the case of rGO, the peak at $\sim 1.1 \mathrm{keV}$ associated with $\mathrm{Na}$ in sodium carboxylate moieties probably originating from $\mathrm{NaOH}$ contained in the reaction medium.

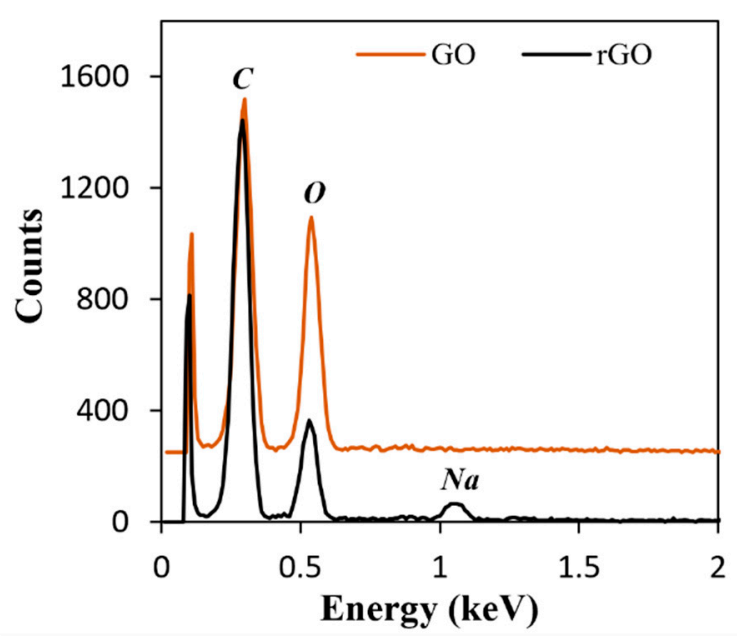

Figure 9. EDX spectra of GO and rGO synthesized using lemon juice (the peak at $0.1 \mathrm{keV}$ is peak originating from background).

The thermal stability of rGO was evaluated by TGA (Figure 10). The TGA curve of GO shows a three-stage weight loss. The first weight loss of approximately $17 \%$ before $120^{\circ} \mathrm{C}$ can be attributed mainly to the removal of water molecules trapped between GO sheets. The next approximately $32 \%$ weight loss up to $300{ }^{\circ} \mathrm{C}$ originates mostly from the pyrolysis of functional groups. The third weight loss from $300{ }^{\circ} \mathrm{C}$ to $800{ }^{\circ} \mathrm{C}$, was approximately $15 \%$, which corresponds to the elimination of remaining functional groups and combustion of the carbon skeleton of GO. The TGA curve of rGO shows the first to third weight losses of approximately 10,15 , and $15 \%$, respectively. The lower weight losses than that of GO, specifically at the first and second stages, are due to the removal of the functional groups. Previous works reported by Gan et al. [31] and Hou et al. [62] also showed a similar trend of weight losses for $\mathrm{GO}$ and $\mathrm{rGO}$. 


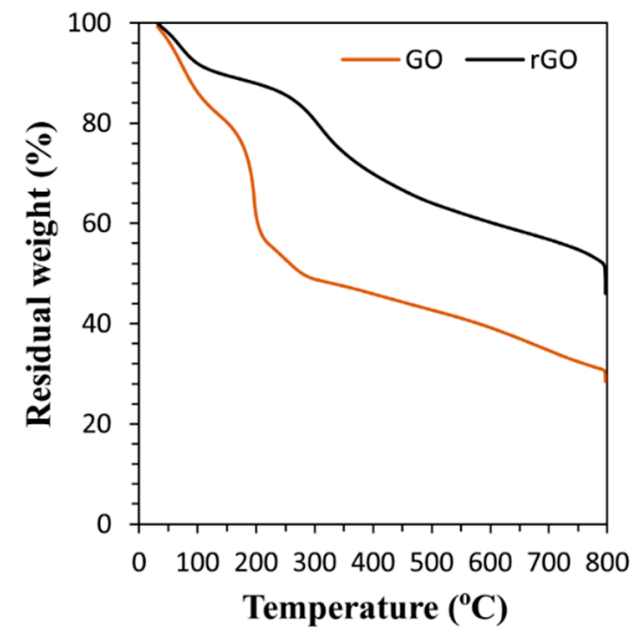

Figure 10. TGA curves of GO and $\mathrm{rGO}$ synthesized using lemon juice (heating rate $=10^{\circ} \mathrm{C} / \mathrm{min}$, $\mathrm{N}_{2}$ flow).

\subsection{Adsorptions Kinetics}

The adsorption of MB onto obtained rGO in an aqueous medium was studied at three different temperatures $(298,313$, and $333 \mathrm{~K}$ ) using $20 \mathrm{mg} / \mathrm{L}$ of MB and $25 \mathrm{mg}$ of rGO. In every case, rapid adsorption took place within the first $15 \mathrm{~min}$, and then the rates were slowed down. The adsorption reached equilibria in $90 \mathrm{~min}$ (Figure 11a) with a removal efficiency of 98 to $99 \%$ (Figure 11b). Thus, we set $90 \mathrm{~min}$ as the reference time for the upcoming adsorption study.
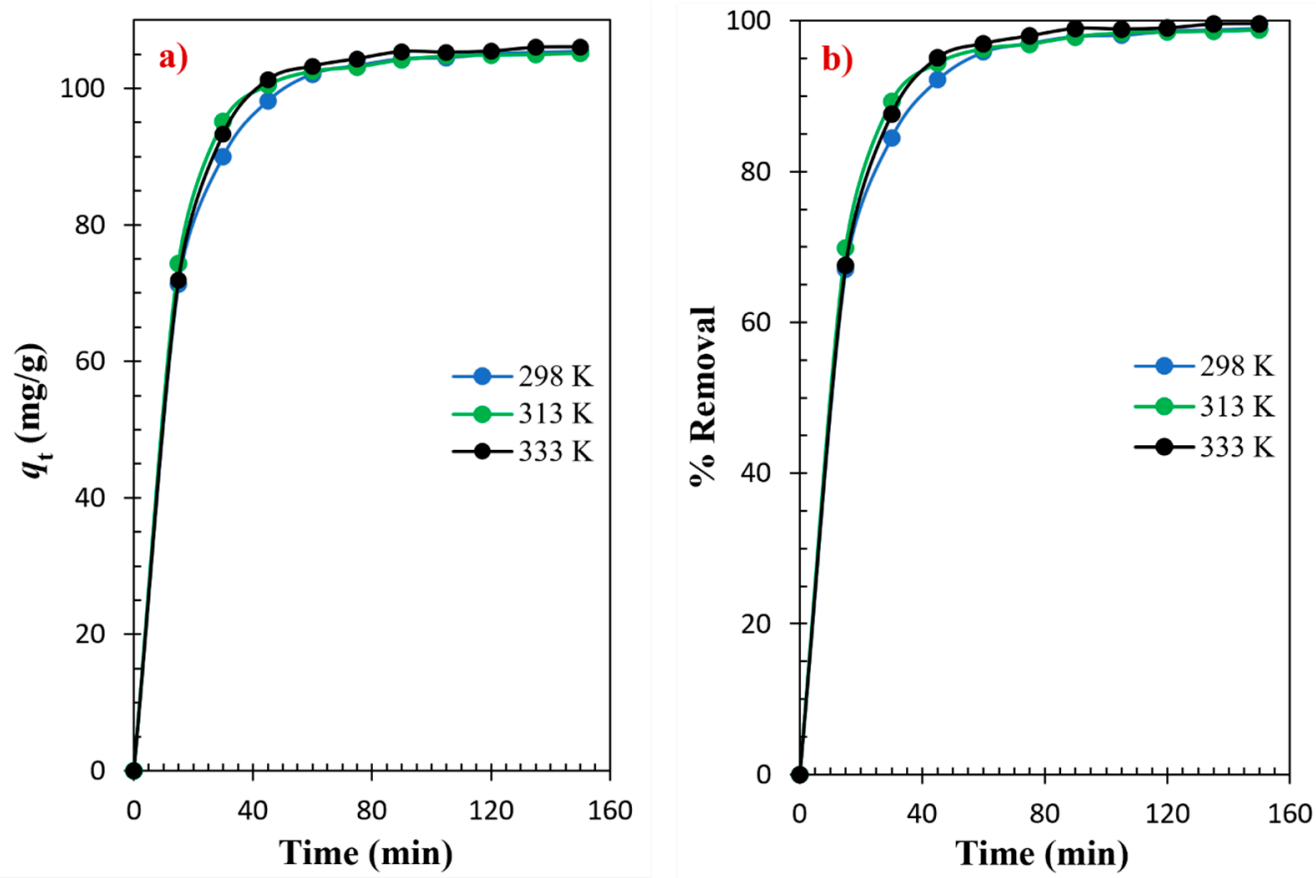

Figure 11. Time dependence of adsorption of MB onto rGO at different temperatures: (a) adsorption capacity and (b) removal efficiency (conditions: $C_{\mathrm{MB} 0}=20 \mathrm{mg} / \mathrm{L}, V=100 \mathrm{~mL}, W_{\mathrm{rGO}}=15 \mathrm{mg}$ ).

The experimental data were fitted to four kinetic models, namely pseudo-first and pseudo-second orders, intraparticle diffusion (IPD), and Boyd kinetic models [29,35,57,63,64] (Figure 12), and the obtained parameters of the adsorption kinetics of MB on rGO are summarized in Table 1. The kinetic model plots fitted the pseudo-second-order model (Figure 12b) better than the pseudo-first-order model (Figure 12a) as can be confirmed 
by the higher correlation coefficients $\left(R^{2}\right)$ exceeding 0.999 . In addition, the calculated $q_{\mathrm{e}}$ (cal) values from the pseudo-first-order model $(93.4,77.1,86.6 \mathrm{mg} / \mathrm{g})$ were lower than the experimental data $(104.3,104.2,105.4 \mathrm{mg} / \mathrm{g})$, while the values from the pseudo-secondorder model $(111.1,108.7,111.1 \mathrm{mg} / \mathrm{g})$ agreed well with the experimental data. The kinetics obeying the pseudo-second-order kinetic model means that the adsorption of MB on rGO synthesized using lemon juice is mostly controlled by chemisorption.

Table 1. Parameters obtained from different kinetics models for $\mathrm{MB}$ adsorption on $\mathrm{rGO}$.

\begin{tabular}{|c|c|c|c|c|c|}
\hline \multirow[t]{2}{*}{ Models and Equations } & \multirow[t]{2}{*}{ Temperature } & \multicolumn{4}{|c|}{ Parameters } \\
\hline & & $K_{1}\left(\times 10^{-2} / \mathrm{min}\right)$ & $q_{\mathrm{cal}}(\mathrm{mg} / \mathrm{g})$ & $q_{\exp }(\mathrm{mg} / \mathrm{g})$ & $R^{2}$ \\
\hline \multirow{4}{*}{$\begin{array}{c}\text { pseudo-first order } \\
\log \left(q_{e}-q_{t}\right)=\log q_{e}-\frac{k_{1}}{2.303} t\end{array}$} & $298 \mathrm{~K}$ & 6.1 & 93.4 & 104.3 & 0.998 \\
\hline & $313 \mathrm{~K}$ & 6.2 & 77.1 & 104.2 & 0.977 \\
\hline & $333 \mathrm{~K}$ & 6.2 & 86.6 & 105.4 & 0.989 \\
\hline & & $\begin{array}{c}K_{2}\left(\times 10^{-3}\right. \\
\mathrm{g} /(\mathrm{mg} \cdot \min )\end{array}$ & $q_{\mathrm{cal}}(\mathrm{mg} / \mathrm{g})$ & $q_{\exp }(\mathrm{mg} / \mathrm{g})$ & $R^{2}$ \\
\hline \multirow{4}{*}{$\begin{array}{l}\text { pseudo-second order } \\
\qquad \frac{t}{q_{t}}=\frac{1}{k_{2} q_{e}^{2}}+\frac{t}{q_{e}}\end{array}$} & $298 \mathrm{~K}$ & 1.4 & 111.1 & 104.3 & 0.999 \\
\hline & $313 \mathrm{~K}$ & 1.9 & 108.7 & 104.2 & 0.999 \\
\hline & $333 \mathrm{~K}$ & 1.6 & 111.1 & 105.4 & 0.999 \\
\hline & & $\begin{array}{c}k_{\mathrm{dif}} \\
\left(\mathrm{mg} /\left(\mathrm{g} \cdot \min ^{1 / 2}\right)\right)\end{array}$ & $R_{\mathrm{i}}$ & $C(\mathrm{mg} / \mathrm{g})$ & $R^{2}$ \\
\hline Intraparticle diffusion & $298 \mathrm{~K}$ & 3.4 & 0.34 & 69.6 & 0.733 \\
\hline$q_{t}=k_{d i f} t^{1 / 2}+C$ & $313 \mathrm{~K}$ & 2.8 & 0.28 & 75.5 & 0.659 \\
\hline \multirow[t]{2}{*}{$R_{i}=\frac{q_{r e f}-C}{q_{r e f}}$} & $333 \mathrm{~K}$ & 3.2 & 0.32 & 72.6 & 0.667 \\
\hline & & & & & $R^{2}$ \\
\hline Boyd kinetic & $298 \mathrm{~K}$ & & & & 0.998 \\
\hline$B_{t}=-0.4977-\ln (1-F)$ & $313 \mathrm{~K}$ & & & & 0.977 \\
\hline$F=\frac{q_{t}}{q_{e}}$ & $333 \mathrm{~K}$ & & & & 0.989 \\
\hline
\end{tabular}

${ }^{\text {a }}$ Conditions: $C_{M B O}=20 \mathrm{mg} / \mathrm{L}, V=100 \mathrm{~mL}, W_{r G O}=15 \mathrm{mg}$.

The transport mechanism of the adsorption process was investigated by the Weber and Morris intra-particle diffusion (IPD) [56] and Boyd kinetic [57] model. IPD model considers multi-linearity in $q_{\mathrm{t}} \mathrm{vs} . t^{1 / 2}$ plots with two or three steps in the whole adsorption process. If a plot becomes a straight line passing through the origin, the intra-particle diffusion is the rate-limiting step. In our study, the plots of the IPD model consisted of two parts and did not pass through the origin (Figure 12c), indicating that intraparticle diffusion is not the rate-limiting step of this adsorption process. The initial and later stages are associated with the transportation of $\mathrm{MB}$ to the exterior surface of $\mathrm{rGO}$ and gradual adsorption, respectively. In addition, calculated $R_{\mathrm{i}}$ values less than 0.5 also testify surface adsorption of MB on rGO [58]. Furthermore, the actual rate-limiting step was determined with the help of the Boyd kinetic model, where the Boyd number, $B_{\mathrm{t}}$ was plotted against time, $t$ (Figure 12d). If a plot shows a linear relationship and passes through the origin, the intra-particle diffusion is the rate-limiting step, on the other hand, if the plot is linear and does not pass through the origin, external mass transfer is the rate-limiting step. In our study, the plots of the Boyd model provided a linear relationship without passing through the origin (Figure 12d). Thus, the transportation of MB to the exterior surface of rGO governs the rate-limiting step of the adsorption process. A similar result was reported for the adsorption of MB on rGO by Bhattacharya et al. [27]. 

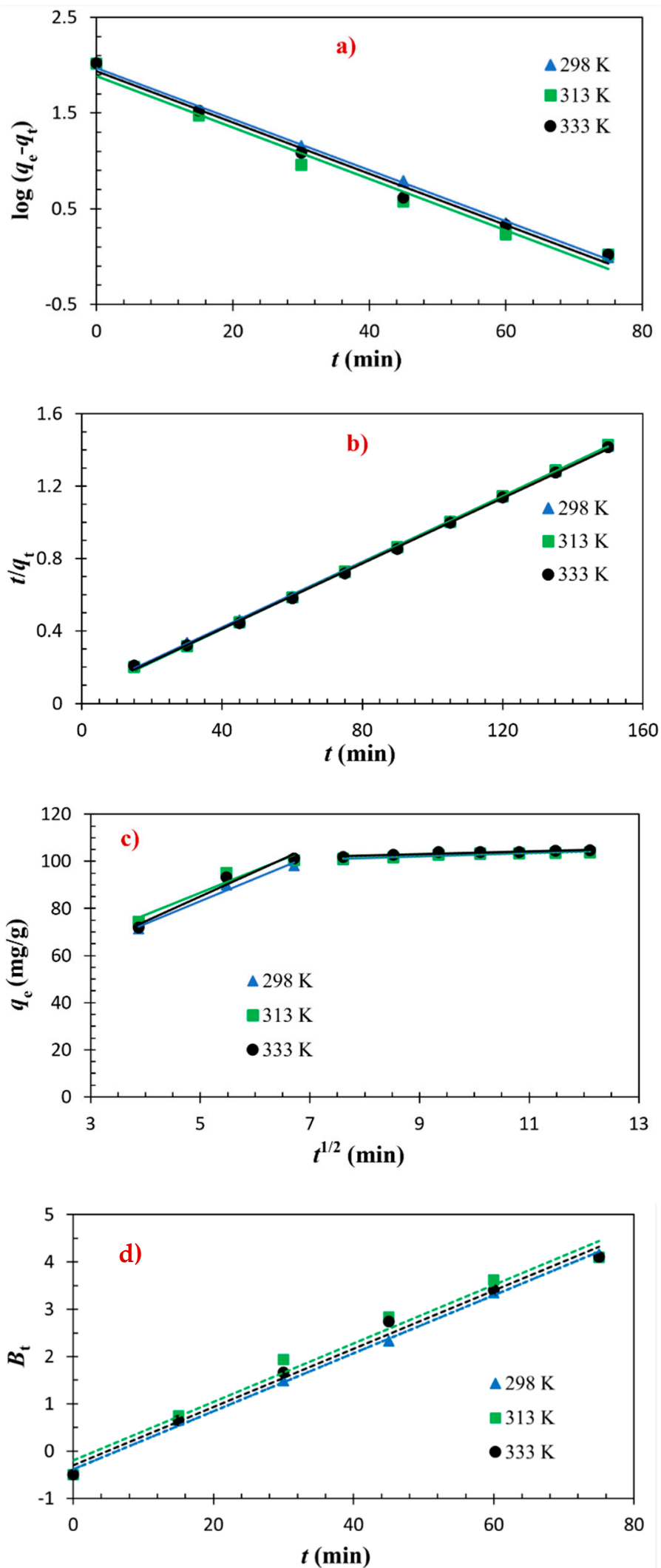

Figure 12. Adsorption kinetics of adsorption of $\mathrm{MB}$ by $\mathrm{rGO}$ for (a) pseudo-first order, (b) pseudo-second order, (c) intraparticle diffusion (IPD), and (d) Boyd kinetic models (conditions: $\left.\mathrm{C}_{\mathrm{MB} 0}=20 \mathrm{mg} / \mathrm{L}, V=100 \mathrm{~mL} ; W_{\mathrm{rGO}}=15 \mathrm{mg}\right)$. 


\subsection{Adsorption Isotherm}

The interaction of dyes with adsorbents can be interpreted from adsorption properties and equilibrium data, which is referred to as the adsorption isotherm. The adsorption isotherms were studied at $298 \mathrm{~K}$ over a span of $90 \mathrm{~min}$. In this study, we applied the Langmuir, Freundlich, and Temkin models. The observed results are displayed in Figure 13 and the parameters are summarized in Table 2 with the mathematical expressions.
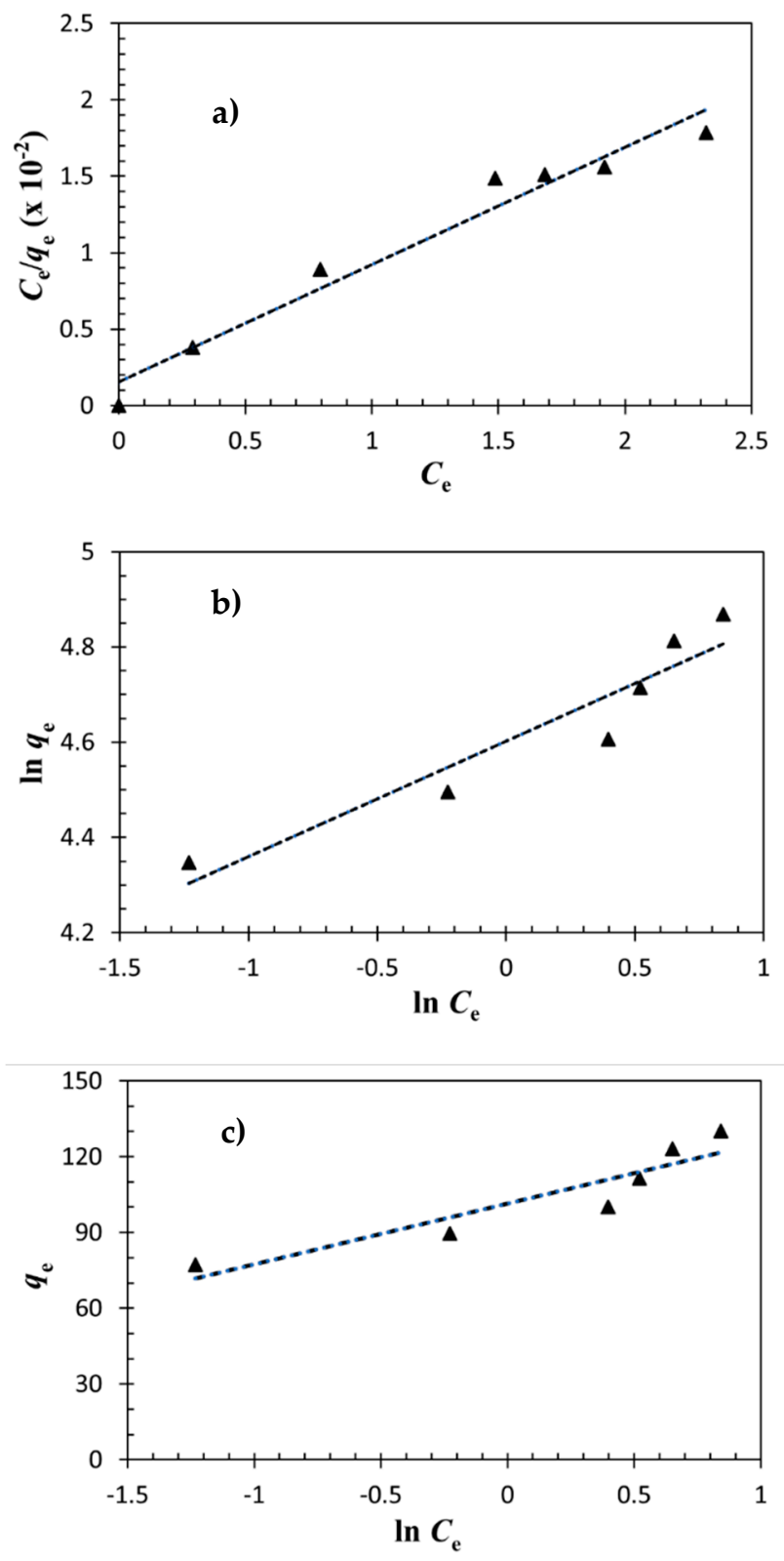

Figure 13. Adsorption isotherms of MB adsorption onto rGO (a) Langmuir, (b) Freundlich, and (c) Temkin models at $298 \mathrm{~K}$. 
Table 2. Constant parameters and correlation coefficients calculated for different adsorption isotherm models at different temperatures for MB adsorption on rGO.

\begin{tabular}{ccc}
\hline Models and Equations & Constants \\
\hline Langmuir & $q_{\mathrm{m}}(\mathrm{mg} / \mathrm{g})$ & \\
\hline & $R_{\mathrm{L}}\left(C_{0}=8 \mathrm{mg} / \mathrm{L}\right.$ & 130.2 \\
\hline & $C_{0}=10 \mathrm{mg} / \mathrm{L}$ & 0.0245 \\
& $C_{0}=12 \mathrm{mg} / \mathrm{L}$ & 0.0197 \\
$\frac{C_{e}}{q_{e}}=\frac{1}{q_{m} b}+\frac{C_{e}}{q_{m}} ; R_{L}=\frac{1}{1+b C_{0}}$ & $C_{0}=14 \mathrm{mg} / \mathrm{L}$ & 0.0164 \\
& $C_{0}=16 \mathrm{mg} / \mathrm{L}$ & 0.0141 \\
& $\left.C_{0}=18 \mathrm{mg} / \mathrm{L}\right)$ & 0.0124 \\
\cline { 2 - 3 } & $b(\mathrm{~L} / \mathrm{mg})$ & 0.011 \\
\hline Freundlich & $R^{2}$ & 4.98 \\
\hline \multirow{2}{*}{$\ln q_{e}=\ln K_{F}+\frac{1}{n} \ln C_{e}$} & $n$ & 0.988 \\
\hline Temkin & $K_{\mathrm{F}}\left(\mathrm{mg} / \mathrm{g}(\mathrm{L} / \mathrm{mg})^{1 / \mathrm{n}}\right)$ & 4.11 \\
\hline \multirow{2}{*}{$q_{e}=B \ln A_{T}+B \ln C_{e} ;$} & $R^{2}$ & 99.7 \\
\cline { 2 - 3 } considering $B=\frac{R T}{b_{T}}$ & $b_{\mathrm{T}}$ & 0.898 \\
\cline { 2 - 3 } & $A_{\mathrm{T}}(\mathrm{L} / \mathrm{g})$ & 102.76 \\
\hline
\end{tabular}

The adsorption behavior fitted best to Langmuir's model. The $C_{\mathrm{e}} / q_{\mathrm{e}}$ vs. $C_{\mathrm{e}}$ plot for the adsorption of $\mathrm{MB}$ on $\mathrm{rGO}$ shows a linear relationship with a good correlation coefficient $\left(R^{2}\right)$ of 0.988 . By contrast, the plots of Freundlich and Temkin models, typically suitable for systems with heterogeneous surface and adsorbate-adsorbate interactions respectively, are not linear with low $R^{2}$. This result indicates the homogeneous surface of rGO for monolayered adsorption. In addition, the dimensionless constant $R_{\mathrm{L}}$ referred to as the separation factor or the equilibrium parameter was calculated, and the obtained values (Table 2) lie between 0 to 1 , indicating favorable adsorption isotherm. Moreover, the calculated maximum amount of dye per unit weight of adsorbent for complete monolayer coverage $\left(q_{\mathrm{m}}\right)$ value was comparable to the experimental values, testifying to the applicability of the Langmuir isotherm model. Compared with other reported graphene-based adsorbents, $\mathrm{rGO}$ produced in this study exhibits a qm value $(130.2 \mathrm{mg} / \mathrm{g})$ higher than exfoliated GO $(17.3 \mathrm{mg} / \mathrm{g})$ [57], rGO-based hydrogel $(7.85 \mathrm{mg} / \mathrm{g})$ [11], nanocomposite of $\beta$-cyclodextrin/magnetic GO $(94 \mathrm{mg} / \mathrm{g})$ [65], interconnected rGO $(106.0 \mathrm{mg} / \mathrm{g})[66], \mathrm{rGO}(121.95 \mathrm{mg} / \mathrm{g})$ synthesized using citric acid [35], glycine-functionalize rGO $(117.6 \mathrm{mg} / \mathrm{g})$ [63], suggesting that lemon juice-based $\mathrm{rGO}$ is a prominent candidate for removal of organic pollutants.

\subsection{Effect of Mass of $r G O$}

The maximum efficiency of this rGO toward the adsorptions of MB over rGO was investigated using different masses of $\mathrm{rGO}(4-9 \mathrm{mg})$ toward a fixed initial concentration of MB $(20 \mathrm{mg} / \mathrm{L})$ at $298 \mathrm{~K}$. The effect of the mass of rGO on the adsorption of MB is demonstrated in Figure 14. The removal efficiency of MB increased from 69.0 to $99.3 \%$ by an increase of rGO from 4 to $9 \mathrm{mg}$ due to the increase in the adsorption sites. In contrast, the adsorption capacity dropped from 143.6 to $89.0 \mathrm{mg} / \mathrm{g}$ as the increase of mass of rGO from 5 to $9 \mathrm{mg}$ due to the increase in the unutilized adsorption sites. 


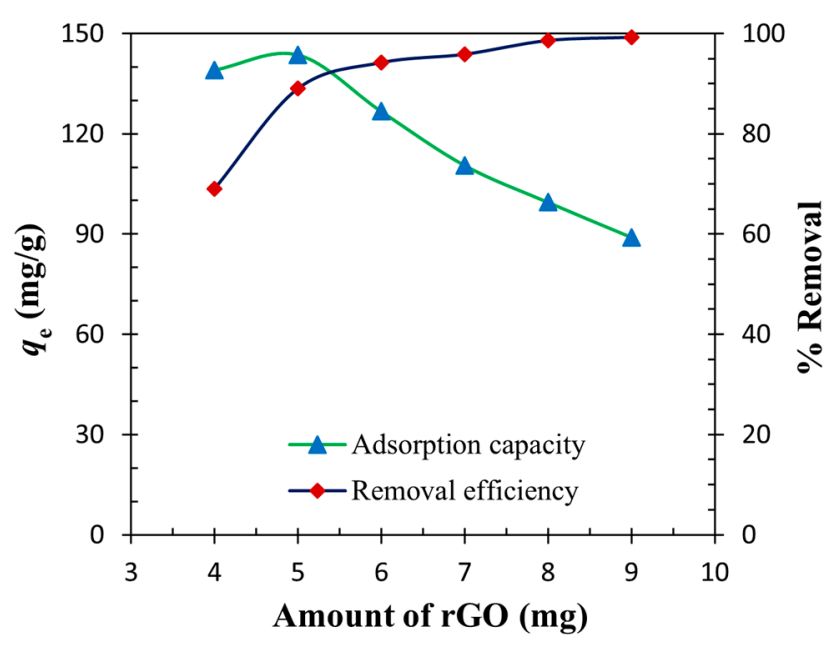

Figure 14. Effect of the mass of $\mathrm{rGO}$ on the adsorption process $\left(C_{\mathrm{MB} 0}=20 \mathrm{mg} / \mathrm{L}, V=50 \mathrm{~mL}\right.$, $T=298 \mathrm{~K})$.

\subsection{Effect of the Initial Concentration of $M B$}

The effect of the initial concentration of MB on the adsorption process was demonstrated in Figure 15. The experiments were carried out using $10 \mathrm{mg}$ of rGO to $100 \mathrm{~mL}$ of MB solution at $298 \mathrm{~K}$. The removal efficiency decreased from 96.6 to $67 \%$ as the increase of the concentration of $\mathrm{MB}$ from 8 to $18 \mathrm{mg} / \mathrm{L}$ with a steady-state (87.3 to $85.1 \%)$ at the concentration range of 12 to $18 \mathrm{mg} / \mathrm{L}$. At lower concentrations of MB, enough amounts of $\mathrm{rGO}$ resulted in high efficiency. As the increase of concentration of $\mathrm{MB}$, the active sites become saturated, resulting in lower dye removal efficiency in spite of the increase of $q_{\mathrm{e}}$.

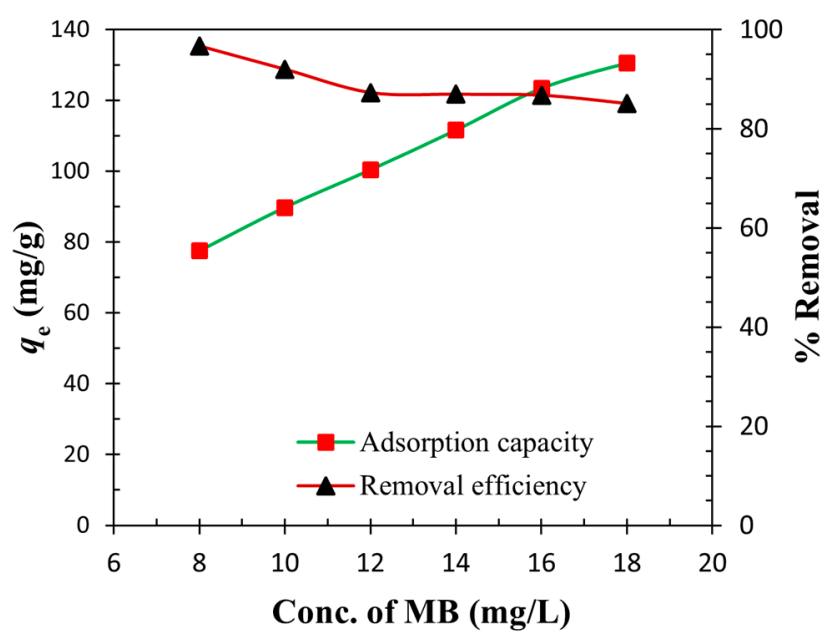

Figure 15. Effect of the initial concentration of $\mathrm{MB}$ on the adsorption process $\left(W_{\mathrm{rGO}}=10 \mathrm{mg}\right.$, $V=100 \mathrm{~mL}, T=298 \mathrm{~K})$.

\subsection{Effect of $p H$}

The effect of $\mathrm{pH}$ was investigated at $298 \mathrm{~K}$ using $16 \mathrm{mg} / \mathrm{L} \mathrm{MB}$ solution with $8 \mathrm{mg}$ of rGO (Figure 16). The removal efficiency increased with increasing $\mathrm{pH}$. Under highly acidic conditions, the basic moieties in $\mathrm{MB}(\mathrm{pKa}=2.6)$ accept protons to make MB di-cationic, and the high polarity of $\mathrm{MB}$ results in low affinity with the hydrophobic rGO surface, leading to very low removal efficiency. As the $\mathrm{pH}$ gets higher, $\mathrm{MB}$ becomes stably mono-cationic with a moderate amphiphilicity, and the adsorption becomes preferable to enhance the removal efficiency $[54,67,68]$. It is reported that the decrease in the cationic nature of MB in basic media increasingly facilitates its adsorption $[54,69]$. 


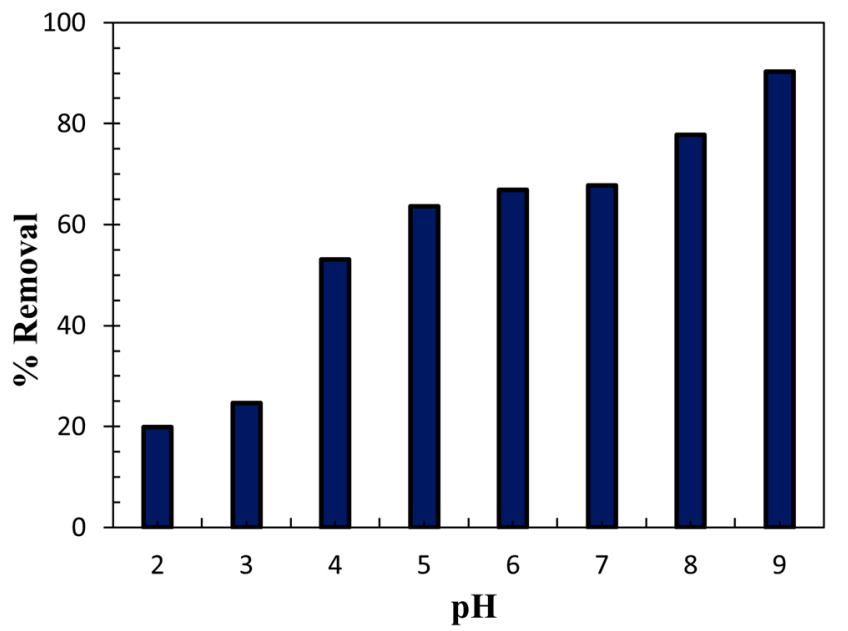

Figure 16. Effect of $\mathrm{pH}$ on the adsorption of $\mathrm{MB}$ on $\mathrm{rGO}\left(C_{\mathrm{MB} 0}=16 \mathrm{mg} / \mathrm{L}, W_{r_{\mathrm{GO}}}=8 \mathrm{mg}, V=100 \mathrm{~mL}\right.$, $T=298 \mathrm{~K})$.

\subsection{Recycling and Reuse Study}

The reusability of rGO was examined by four successive adsorption/desorption cycles according to the method developed by Aboelfetoh et al. [70] (Figure 17). The desorption of $\mathrm{MB}$ from spent $\mathrm{rGO}$ was conducted by separating rGO by centrifugation, followed by sequential washing with $0.1 \mathrm{M} \mathrm{NaOH}(a q)$, diluted ethanol $(a q)$, and distilled water. Figure 17 indicates that the removal efficiency was above $80 \%$ even after four cycles of its usage with a decrease in the efficiency from 95.5 to $80.4 \%$. This decrease can be attributed to the incomplete recovery of adsorption sites because some of the adsorption sites were blocked by a trace amount of $\mathrm{MB}$ or its degraded products that are produced at higher $\mathrm{pH}$ during the desorption processes as confirmed by the appearance of two tiny peaks at 1375 and $1315 \mathrm{~cm}^{-1}$ assignable to the aromatic rings in the FTIR spectrum of rGO after being used for three consecutive adsorption-desorption cycles (Figure 18). Presumably, $\mathrm{MB}$ or its degraded products are attached with rGO either by physical adsorption or any chemical bond formation with the functional groups of rGO. By contrast, the morphology of rGO was not changed as confirmed from the SEM image of rGO (Figure 19) showing the exfoliated and separated few layers of sheets used for three consecutive adsorptiondesorption cycles. Thus, it can be supposed that the high significant reusability of rGO suggests its potential for broad applications.

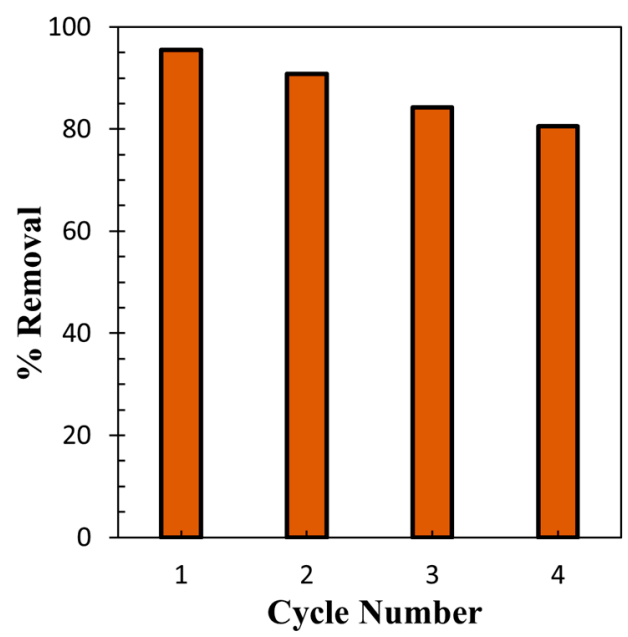

Figure 17. Recycling performance of rGO for capturing of $\mathrm{MB}$ up to 4 cycles $\left(C_{\mathrm{MB} 0}=20 \mathrm{mg} / \mathrm{L}\right.$, $\left.W_{\mathrm{rGO}}=8 \mathrm{mg}, V=100 \mathrm{~mL}, T=298 \mathrm{~K}\right)$. 


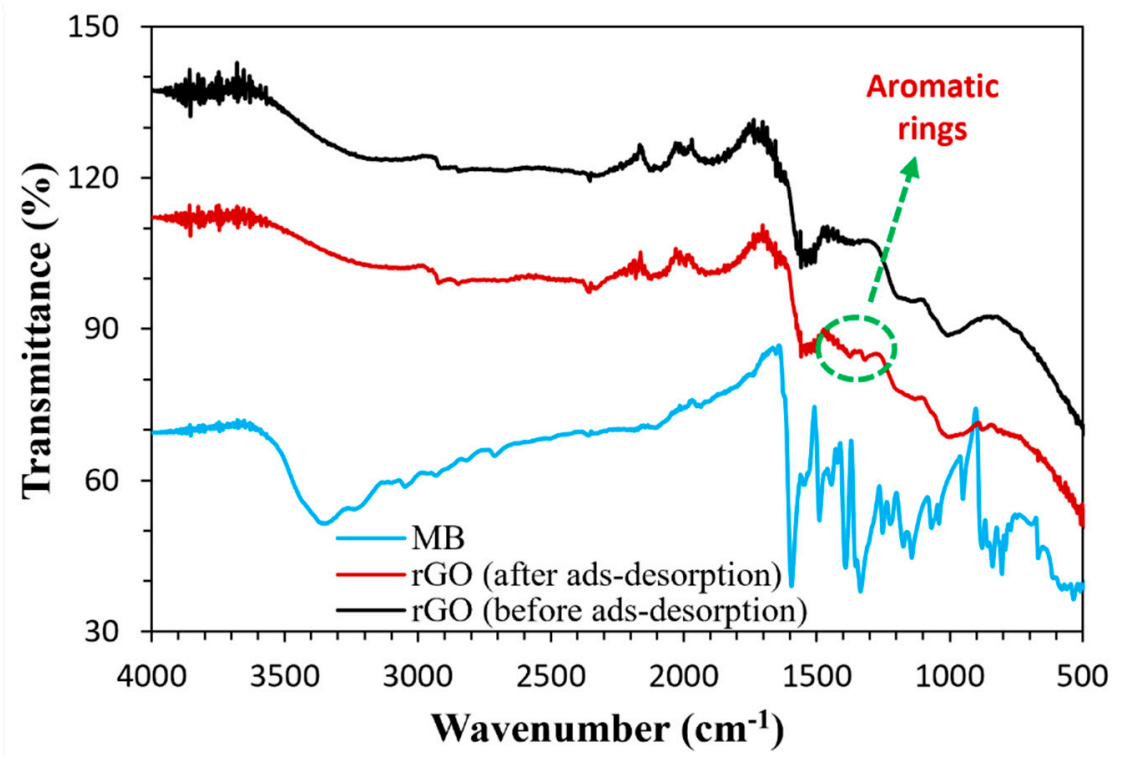

Figure 18. FTIR spectra of MB and rGO before and after three consecutive adsorption-desorption cycles.

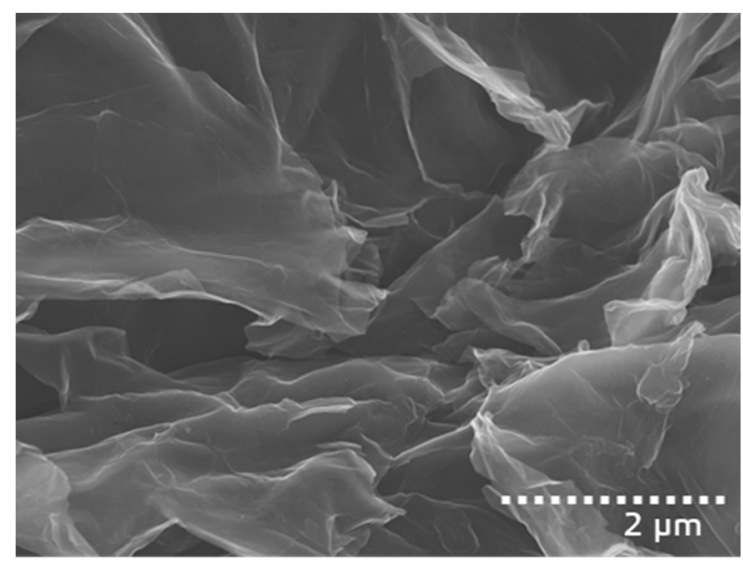

Figure 19. SEM images of rGO used for three consecutive adsorption-desorption cycles.

\section{Conclusions}

A successful green approach was demonstrated for the reduction of GO to exfoliated rGO using lemon juice as an efficient, cheap, and green reducing agent. The excellence of this method is its low cost, avoidance of toxic agents and hazardous wastes, worthy elimination of functional groups from GO, and scalability. The adsorption study performed on $\mathrm{MB}$ revealed that $\mathrm{rGO}$ exhibits fast dye adsorption with a maximum adsorption capacity of $132.2 \mathrm{mg} / \mathrm{g}$. The adsorption process follows pseudo-second-order kinetics and is best described by the Langmuir isotherm model. In addition, synthesized rGO showed good recyclability. The present study indicates that lemon juice is an ideal substitute for hazardous reducing agents like sodium borohydride, hydrazine, and dimethylhydrazine in the large-scale synthesis of rGO. The high adsorption ability of rGO originates from the high efficiency of exfoliation. Therefore, further investigation on the applications of lemon juice-based rGO will lead to industrial applications.

Author Contributions: Conceptualization, M.M. and B.O.; methodology, data investigation, data curation, and writing — original draft, M.M.; supervision, B.O.; writing—review and editing, M.M. and B.O. All authors have read and agreed to the published version of the manuscript.

Funding: This research received no external funding. 
Institutional Review Board Statement: Not applicable.

Informed Consent Statement: Not applicable.

Data Availability Statement: Not applicable.

Acknowledgments: M.M. gratefully acknowledges the Ministry of Education, Culture, Sports, Science and Technology, Japan, for providing the Japanese Government (Monbukagakusho: MEXT) Scholarship.

Conflicts of Interest: The authors declare no conflict of interest.

\section{References}

1. Novoselov, K.S.; Geim, A.K.; Morozov, S.V.; Jiang, D.; Zhang, Y.; Dubonos, S.V.; Grigorieva, I.V.; Firsov, A.A. Electric field effect in atomically thin carbon films. Science 2004, 306, 666-669. [CrossRef]

2. Liu, J.; Fu, S.; Yuan, B.; Li, Y.; Deng, Z. Toward a Universal “Adhesive Nanosheet” for the Assembly of Multiple Nanoparticles Based on a Protein-Induced Reduction/Decoration of Graphene Oxide. J. Am. Chem. Soc. 2010, 132, 7279-7281. [CrossRef] [PubMed]

3. Zhu, C.; Guo, S.; Fang, Y.; Dong, S. Reducing Sugar: New Functional Molecules for the Green Synthesis of Graphene Nanosheets. ACS Nano 2010, 4, 2429-2437. [CrossRef] [PubMed]

4. Ciesielski, A.; Samorì, P. Graphene via sonication assisted liquid-phase exfoliation. Chem. Soc. Rev. 2014, 43, 381-398. [CrossRef] [PubMed]

5. González-Domínguez, J.M.; León, V.; Lucío, M.I.; Prato, M.; Vázquez, E. Production of ready-to-use few-layer graphene in aqueous suspensions. Nat. Protoc. 2018, 13, 495-506. [CrossRef] [PubMed]

6. Wang, Y.; Shi, Z.; Yin, J. Facile Synthesis of Soluble Graphene via a Green Reduction of Graphene Oxide in Tea Solution and Its Biocomposites. ACS Appl. Mater. Interfaces 2011, 3, 1127-1133. [CrossRef]

7. Gao, M.; Li, X.; Qi, D.; Lin, J. Green Synthesis of Porous Spherical Reduced Graphene Oxide and Its Application in Immobilized Pectinase. ACS Omega 2020, 5, 32706-32714. [CrossRef] [PubMed]

8. Joshi, S.; Siddiqui, R.; Sharma, P.; Kumar, R.; Verma, G.; Saini, A. Green synthesis of peptide functionalized reduced graphene oxide (rGO) nano bioconjugate with enhanced antibacterial activity. Sci. Rep. 2020, 10, 1-11. [CrossRef]

9. Poudel, M.B.; Awasthi, G.P.; Kim, H.J. Novel insight into the adsorption of $\mathrm{Cr}(\mathrm{VI})$ and $\mathrm{Pb}(\mathrm{II})$ ions by MOF derived Co-Al layered double hydroxide @hematite nanorods on 3D porous carbon nanofiber network. Chem. Eng. J. 2021, 417, 129312. [CrossRef]

10. Cai, X.; Lai, L.; Shen, Z.; Lin, J. Graphene and graphene-based composites as Li-ion battery electrode materials and their ap-plication in full cells. J. Mater. Chem. A 2017, 5, 15423-15446. [CrossRef]

11. Tiwari, J.N.; Mahesh, K.; Le, N.; Kemp, K.; Timilsina, R.; Tiwari, R.N.; Kim, K.S. Reduced graphene oxide-based hydrogels for the efficient capture of dye pollutants from aqueous solutions. Carbon 2013, 56, 173-182. [CrossRef]

12. Chia, J.S.Y.; Tan, M.; Khiew, P.; Chin, J.; Lee, H.W.; Bien, D.; Siong, C.W. A novel one step synthesis of graphene via sonochemicalassisted solvent exfoliation approach for electrochemical sensing application. Chem. Eng. J. 2014, 249, 270-278. [CrossRef]

13. Goud, K.Y.; Hayat, A.; Catanante, G.; Satyanarayana, M.; Gobi, K.V.; Marty, J.L. An electrochemical aptasensor based on functionalized graphene oxide assisted electrocatalytic signal amplification of methylene blue for aflatoxin B1 detection. Electrochimica Acta 2017, 244, 96-103. [CrossRef]

14. Jiang, C.; An, D.; Wang, Z.; Zhang, S.; An, X.; Bo, J.; Yan, G.; Moon, K.-S.; Wong, C. A sustainable reduction route of graphene oxide by industrial waste lignin for versatile applications in energy and environment. J. Clean. Prod. 2020, 268, 122019. [CrossRef]

15. Sun, X.; Liu, Z.; Welsher, K.; Robinson, J.T.; Goodwin, A.; Zaric, S.; Dai, H. Nano-graphene oxide for cellular imaging and drug delivery. Nano Res. 2008, 1, 203-212. [CrossRef] [PubMed]

16. Ferrari, A.C.; Bonaccorso, F.S.; Fal'Ko, V.; Novoselov, K.; Roche, S.; Bøggild, P.; Borini, S.; Koppens, F.H.L.; Palermo, V.; Pugno, N.; et al. Science and technology roadmap for graphene, related two-dimensional crystals, and hybrid systems. Nanoscale 2014, 7 , 4598-4810. [CrossRef]

17. Sharma, N.; Sharma, V.; Jain, Y.; Kumari, M.; Gupta, R.; Sharma, S.K.; Sachdev, K. Synthesis and Characterization of Graphene Oxide (GO) and Reduced Graphene Oxide (rGO) for Gas Sensing Application. Macromol. Symp. 2017, 376. [CrossRef]

18. Poudel, M.B.; Kim, H.J. Synthesis of high-performance nickel hydroxide nanosheets/gadolinium doped- $\alpha-\mathrm{MnO}_{2}$ composite nanorods as cathode and $\mathrm{Fe}_{3} \mathrm{O}_{4} / \mathrm{GO}$ nanospheres as anode for an all-solid-state asymmetric supercapacitor. J. Energy Chem. 2022, 64, 475-484. [CrossRef]

19. Feng, H.; Cheng, R.; Zhao, X.; Duan, X.; Li, J. A low-temperature method to produce highly reduced graphene oxide. Nat. Commun. 2013, 4, 1539. [CrossRef] [PubMed]

20. De Silva, K.; Huang, H.-H.; Joshi, R.; Yoshimura, M. Chemical reduction of graphene oxide using green reductants. Carbon 2017, 119, 190-199. [CrossRef]

21. Shin, H.-J.; Kim, K.K.; Benayad, A.; Yoon, S.-M.; Park, H.K.; Jung, I.-S.; Jin, M.H.; Jeong, H.-K.; Kim, J.M.; Choi, J.-Y.; et al. Efficient Reduction of Graphite Oxide by Sodium Borohydride and Its Effect on Electrical Conductance. Adv. Funct. Mater. 2009, 19, 1987-1992. [CrossRef] 
22. Stankovich, S.; Dikin, D.A.; Piner, R.D.; Kohlhaas, K.A.; Kleinhammes, A.; Jia, Y.; Wu, Y.; Nguyen, S.; Ruoff, R.S. Synthesis of graphene-based nanosheets via chemical reduction of exfoliated graphite oxide. Carbon 2007, 45, 1558-1565. [CrossRef]

23. Li, D.; Müller, M.B.; Gilje, S.; Kaner, R.B.; Wallace, G.G. Processable aqueous dispersions of graphene nanosheets. Nat. Nanotechnol. 2008, 3, 101-105. [CrossRef]

24. Wang, G.; Yang, J.; Park, J.; Gou, X.; Wang, B.; Liu, H.; Yao, J. Facile synthesis and characterization of graphene nanosheets. J. Phys. Chem. C 2008, 112, 8192-8195. [CrossRef]

25. Zhang, C.; Lv, W.; Zhang, W.; Zheng, X.; Wu, M.-B.; Wei, W.; Tao, Y.; Li, Z.; Yang, Q.-H. Reduction of Graphene Oxide by Hydrogen Sulfide: A Promising Strategy for Pollutant Control and as an Electrode for Li-S Batteries. Adv. Energy Mater. 2013, 4, 1301565. [CrossRef]

26. Wang, Y.; Zhang, P.; Liu, C.F.; Zhan, L.; Li, Y.F.; Huang, C.Z. Green and easy synthesis of biocompatible graphene for use as an anticoagulant. RSC Adv. 2012, 2, 2322-2328. [CrossRef]

27. De Silva, K.K.H.; Huang, H.-H.; Yoshimura, M. Progress of reduction of graphene oxide by ascorbic acid. Appl. Surf. Sci. 2018, 447, 338-346. [CrossRef]

28. Sadhukhan, S.; Ghosh, T.K.; Rana, D.; Roy, I.; Bhattacharyya, A.; Sarkar, G.; Chakraborty, M.; Chattopadhyay, D. Studies on synthesis of reduced graphene oxide (RGO) via green route and its electrical property. Mater. Res. Bull. 2016, 79, 41-51. [CrossRef]

29. Bhattacharya, G.; Sas, S.; Wadhwa, S.; Mathur, A.; McLaughlin, J.; Roy, S.S. Aloe vera assisted facile green synthesis of reduced graphene oxide for electrochemical and dye removal applications. RSC Adv. 2017, 7, 26680-26688. [CrossRef]

30. Manchala, S.; Tandava, V.S.R.K.; Jampaiah, D.; Bhargava, S.K.; Shanker, V. Novel and Highly Efficient Strategy for the Green Synthesis of Soluble Graphene by Aqueous Polyphenol Extracts of Eucalyptus Bark and Its Applications in High-Performance Supercapacitors. ACS Sustain. Chem. Eng. 2019, 7, 11612-11620. [CrossRef]

31. Gan, L.; Li, B.; Chen, Y.; Yu, B.; Chen, Z. Green synthesis of reduced graphene oxide using bagasse and its application in dye removal: A waste-to-resource supply chain. Chemosphere 2018, 219, 148-154. [CrossRef]

32. Wijaya, R.; Andersan, G.; Santoso, S.P.; Irawaty, W. Green Reduction of Graphene Oxide using Kaffir Lime Peel Extract (Citrus hystrix) and Its Application as Adsorbent for Methylene Blue. Sci. Rep. 2020, 10, 1-9. [CrossRef] [PubMed]

33. Maddinedi, S.B.; Mandal, B.K.; Vankayala, R.; Kalluru, P.; Pamanji, S.R. Bioinspired reduced graphene oxide nanosheets using Terminalia chebula seeds extract. Spectrochim. Acta Part A Mol. Biomol. Spectrosc. 2015, 145, 117-124. [CrossRef] [PubMed]

34. Haghighi, B.; Tabrizi, M.A. Green-synthesis of reduced graphene oxide nanosheets using rose water and a survey on their characteristics and applications. RSC Adv. 2013, 3, 13365-13371. [CrossRef]

35. Arias, F.A.; Guevara, M.; Tene, T.; Angamarca, P.; Molina, R.; Valarezo, A.; Salguero, O.; Gomez, C.V.; Arias, M.; Caputi, L.S. The Adsorption of Methylene Blue on Eco-Friendly Reduced Graphene Oxide. Nanomaterials 2020, 10, 681. [CrossRef] [PubMed]

36. Hsieh, C.-Y.; Hsieh, S.-L.; Ciou, J.-Y.; Huang, Y.-W.; Leang, J.-Y.; Chen, M.-H.; Hou, C.-Y. Lemon juice bioactivity in vitro increased with lactic acid fermentation. Int. J. Food Prop. 2020, 24, 28-40. [CrossRef]

37. 'World's Top Lemon Producing Countries. Available online: www.atlasbig.com (accessed on 8 October 2021).

38. Cicero, N.; Corsaro, C.; Salvo, A.; Vasi, S.; Giofrè, S.V.; Ferrantelli, V.; Di Stefano, V.; Mallamace, D.; Dugo, G. The metabolic profile of lemon juice by proton HR-MAS NMR: The case of the PGI Interdonato Lemon of Messina. Nat. Prod. Res. 2015, 29, 1-9. [CrossRef]

39. Alfadul, S.M.; Hassan, B.H. Chemical Composition of Natural Juices Combining Lemon and Dates. ETP Int. J. Food Eng. 2016. [CrossRef]

40. Mucci, A.; Parenti, F.; Righi, V.; Schenetti, L. Citron and lemon under the lens of HR-MAS NMR spectroscopy. Food Chem. 2013, 141, 3167-3176. [CrossRef]

41. Yu, L.; Liao, Z.; Zhao, Y.; Zeng, X.; Yang, B.; Bai, W. Metabolomic analyses of dry lemon slice during storage by NMR. Food Front. 2020, 1, 180-191. [CrossRef]

42. Mosae Selvakumar, P.; Antonyraj, C.A.; Babu, R.; Dakhsinamurthy, A.; Manikandan, N.; Palanivel, A. Green synthesis and antimicrobial activity of monodispersed silver nanoparticles synthesized using lemon extract. Synth. React. Inorg. Met. Nano-Metal. Chem. 2016, 46, 291-294. [CrossRef]

43. Sujitha, M.V.; Kannan, S. Green synthesis of gold nanoparticles using Citrus fruits (Citrus limon, Citrus reticulata and Citrus sinensis) aqueous extract and its characterization. Spectrochim. Acta Part A Mol. Biomol. Spectrosc. 2013, 102, 15-23. [CrossRef] [PubMed]

44. Mahiuddin, M.; Ochiai, B. Green synthesis of crystalline bismuth nanoparticles using lemon juice. RSC Adv. 2021, 11, 26683-26686. [CrossRef]

45. Klimek-Szczykutowicz, M.; Szopa, A.; Ekiert, H. Citrus limon (lemon) phenomenon-A review of the chemistry, pharmacological prop-erties, applications in the modern pharmaceutical, food, and cosmetics industries, and biotechnological studies. Plants 2020, 9, 119. [CrossRef]

46. Gurbani, N.; Han, C.-P.; Marumoto, K.; Liu, R.-S.; Choudhary, R.J.; Chouhan, N. Biogenic Reduction of Graphene Oxide: An Efficient Superparamagnetic Material for Photocatalytic Hydrogen Production. ACS Appl. Energy Mater. 2018, 1, 5907-5918. [CrossRef]

47. Hummers, W.S., Jr.; Offeman, R.E. Preparation of Graphitic Oxide. J. Am. Chem. Soc. 1958, 80, 1339. [CrossRef]

48. Poudel, M.B.; Yu, C.; Kim, H.J. Synthesis of conducting bifunctional polyaniline@Mn- $\mathrm{TiO}_{2}$ nanocomposites for supercapacitor electrode and visible light driven photocatalysis. Catalysts 2020, 10, 546. [CrossRef] 
49. Jin, Y.; Zheng, Y.; Podkolzin, S.G.; Lee, W. Band gap of reduced graphene oxide tuned by controlling functional groups. J. Mater. Chem. C 2020, 8, 4885-4894. [CrossRef]

50. Mathkar, A.; Tozier, D.; Cox, P.; Ong, P.; Galande, C.; Balakrishnan, K.; Reddy, A.L.M.; Ajayan, P.M. Controlled, Stepwise Reduction and Band Gap Manipulation of Graphene Oxide. J. Phys. Chem. Lett. 2012, 3, 986-991. [CrossRef]

51. Velasco-Soto, M.A.; Pérez-García, S.A.; Alvarez-Quintana, J.; Cao, Y.; Nyborg, L.; Licea-Jiménez, L. Selective band gap manipulation of graphene oxide by its reduction with mild reagents. Carbon 2015, 93, 967-973. [CrossRef]

52. Abdolhosseinzadeh, S.; Asgharzadeh, H.; Kim, H.S. Fast and fully-scalable synthesis of reduced graphene oxide. Sci. Rep. 2015, 5, 10160. [CrossRef] [PubMed]

53. Ahmad, S.; Ahmad, A.; Khan, S.; Ahmad, S.; Khan, I.; Zada, S.; Fu, P. Algal extracts based biogenic synthesis of reduced graphene oxides (rGO) with enhanced heavy metals adsorption capability. J. Ind. Eng. Chem. 2018, 72, 117-124. [CrossRef]

54. Siong, V.L.E.; Lee, K.M.; Juan, J.C.; Lai, C.W.; Tai, X.H.; Khe, C.S. Removal of methylene blue dye by solvothermally reduced graphene oxide: A metal-free adsorption and photodegradation method. RSC Adv. 2019, 9, 37686-37695. [CrossRef]

55. Penki, T.R.; Valurouthu, G.; Shivakumara, S.; Sethuraman, V.A.; Munichandraiah, N. In situ synthesis of bismuth (Bi)/reduced graphene oxide (rGO) nanocomposites as high-capacity anode materials for a Mg-ion battery. N. J. Chem. 2018, 42, 5996-6004. [CrossRef]

56. Qiao, S.-J.; Xu, X.-N.; Qiu, Y.; Xiao, H.-C.; Zhu, Y.-F. Simultaneous Reduction and Functionalization of Graphene Oxide by 4-Hydrazinobenzenesulfonic Acid for Polymer Nanocomposites. Nanomaterials 2016, 6, 29. [CrossRef]

57. Ramesha, G.; Kumara, A.V.; Muralidhara, H.; Sampath, S. Graphene and graphene oxide as effective adsorbents toward anionic and cationic dyes. J. Colloid Interface Sci. 2011, 361, 270-277. [CrossRef]

58. Ramesha, G.K.; Sampath, S. Electrochemical reduction of oriented graphene oxide films: An in-situ Raman spectro electrochemical study. J. Phys. Chem. C 2009, 113, 7985-7989. [CrossRef]

59. Kolya, H.; Kuila, T.; Kim, N.H.; Lee, J.H. Bioinspired silver nanoparticles/reduced graphene oxide nanocomposites for catalytic reduction of 4-nitrophenol, organic dyes and act as energy storage electrode material. Compos. Part B Eng. 2019, 173, 106924. [CrossRef]

60. Johra, F.T.; Lee, J.-W.; Jung, W.-G. Facile and safe graphene preparation on solution based platform. J. Ind. Eng. Chem. 2014, 20, 2883-2887. [CrossRef]

61. Chu, H.-J.; Lee, C.-Y.; Tai, N.-H. Green reduction of graphene oxide by Hibiscus sabdariffa L. to fabricate flexible graphene electrode. Carbon 2014, 80, 725-733. [CrossRef]

62. Hou, D.; Liu, Q.; Cheng, H.; Zhang, H.; Wang, S. Green reduction of graphene oxide via Lycium barbarum extract. J. Solid State Chem. 2017, 246, 351-356. [CrossRef]

63. Wang, C.; Ma, G.; Zhou, J.; Zhang, M.; Ma, X.; Duo, F.; Chu, L.; Huang, J.; Su, X. Glycine-functionalized reduced graphene oxide for methylene blue removal. Appl. Organomet. Chem. 2019, 33, e5077. [CrossRef]

64. Shukla, S.P.; Kisku, G.C. Linear and non-linear kinetic modeling for adsorption of disperse dye in batch process. Res. J. Environ. Toxicol. 2015, 9, 320-331. [CrossRef]

65. Wang, C.; Li, B.; Niu, W.; Hong, S.; Saif, B.; Wang, S.; Dong, C.; Shuang, S. $\beta$-Cyclodextrin modified graphene oxide--magnetic nanocomposite for targeted delivery and $\mathrm{pH}$-sensitive release of stereoisomeric anti-cancer drugs. RSC Adv. 2015, 5, 89299-89308. [CrossRef]

66. Mao, B.; Sidhureddy, B.; Thiruppathi, A.R.; Wood, P.C.; Chen, A. Efficient dye removal and separation based on graphene oxide nanomaterials. New J. Chem. 2020, 44, 4519-4528. [CrossRef]

67. Hossain, M.S.; Ochiai, B. Detailed study on rapid removal of cationic dyes using $\mathrm{TiO}_{2}$-poly(3-chloro-2-hydroxypropyl methacrylate) nanocomposite. J. Electrochem. Soc. 2019, 166, B3240-B3245. [CrossRef]

68. Huang, T.; Yan, M.; He, K.; Huang, Z.; Zeng, G.; Chen, A.; Peng, M.; Li, H.; Yuan, L.; Chen, G. Efficient removal of methylene blue from aqueous solutions using magnetic graphene oxide modified zeolite. J. Colloid Interface Sci. 2019, 543, 43-51. [CrossRef]

69. Zarrabi, M.; Haghighi, M.; Alizadeh, R.; Mahboob, S. Solar-light-driven photodegradation of organic dyes on sono-dispersed ZnO nanoparticles over graphene oxide: Sono vs. conventional catalyst design. Sep. Purif. Technol. 2018, 211, 738-752. [CrossRef]

70. Aboelfetoh, E.F.; Gemeay, A.H.; El-Sharkawy, R.G. Effective disposal of methylene blue using green immobilized silver nanoparticles on graphene oxide and reduced graphene oxide sheets through one-pot synthesis. Environ. Monit. Assess. 2020, 192, 355. [CrossRef] [PubMed] 